\title{
Molecular Neurobiology
}

\section{$\alpha$-synuclein aggregates with $\beta$-amyloid or tau in human red blood cells: correlation with antioxidant capability and physical exercise in human healthy subjects \\ --Manuscript Draft--}

\begin{tabular}{|c|c|}
\hline Manuscript Number: & MOLN-D-17-00041R1 \\
\hline Article Type: & Original Article \\
\hline Keywords: & $\begin{array}{l}\text { protein misfolding; Neurodegenerative Diseases; } \alpha \text {-synuclein; } \beta \text {-amyloid; Tau; } \alpha- \\
\text { synuclein heterocomplexes; antioxidant capability; physical exercise. }\end{array}$ \\
\hline Corresponding Author: & $\begin{array}{l}\text { Maria Letizia Trincavelli } \\
\text { Universita degli Studi di Pisa } \\
\text { ITALY }\end{array}$ \\
\hline First Author: & Simona Daniele \\
\hline \multirow[t]{15}{*}{ Order of Authors: } & Simona Daniele \\
\hline & Deborah Pietrobono \\
\hline & Jonathan Fusi \\
\hline & Caterina lofrida \\
\hline & Lucia Chico \\
\hline & Lucia Petrozzi \\
\hline & Annalisa Lo Gerfo \\
\hline & Filippo Baldacci \\
\hline & Fabio Galetta \\
\hline & Gabriele Siciliano \\
\hline & Ubaldo Bonuccelli \\
\hline & Gino Santoro \\
\hline & Maria Letizia Trincavelli \\
\hline & Ferdinando Franzoni \\
\hline & Claudia Martini \\
\hline Abstract: & 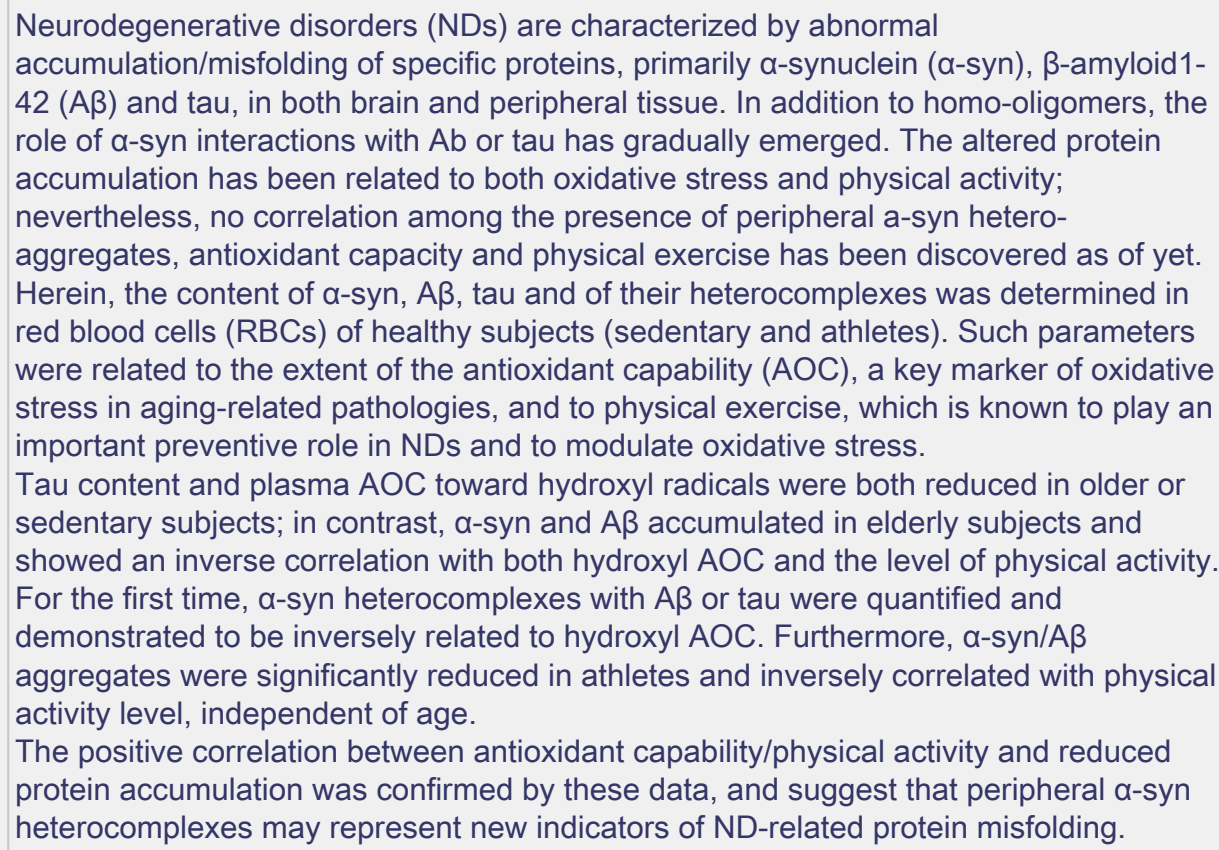 \\
\hline
\end{tabular}




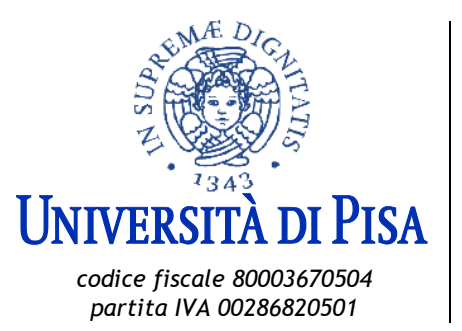

DIPARTIMENTO DI FARMACIA

Via Bonanno, 6 - 56126 Pisa (Italy)

tel. 00390502219500

fax 00390502219608

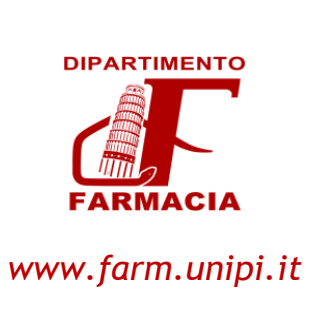

March 29, 2017

\section{Executive Editor}

Molecular Neurobiology

Dear Editor,

Herewith enclosed please find the revised version of our manuscript entitled " $\alpha$-synuclein aggregates with $\beta$-amyloid or tau in human red blood cells: correlation with antioxidant capability and physical exercise in human subjects" by Daniele S. et al.

We are grateful for the opportunity to revise our manuscript and to improve its quality by following the referee's suggestions. We do hope the new version of the manuscript will meet all the requirements for publication in Molecular Neurobiology

Looking forward to hearing from you soon, we thank you and send you our best personal regards.

Sincerely yours,

Maria Letizia Trincavelli and Ferdinando Franzoni 


\section{AMERICAN JOURNAL EXPERTS}

\section{EDITORIAL CERTIFICATE}

This document certifies that the manuscript listed below was edited for proper English language, grammar, punctuation, spelling, and overall style by one or more of the highly qualified native English speaking editors at American Journal Experts.

Manuscript title:

alpha-synuclein aggregates with beta-amyloid or Tau in human red blood cells: correlation with anti-oxidant capability and physical exercise in human subjects

\section{Authors:}

Simona Daniele, Deborah Pietrobono, Jonathan Fusi, Caterina lofrida, Lucia Chico, Lucia Petrozzi, Annalisa Lo Gerfo, Filippo Baldacci, Fabio Galetta, Gabriele Siciliano, Ubaldo Bonuccelli, Gino Santoro, Maria Letizia Trincavelli, Ferdinando Franzoni, Claudia Martini

\section{Date Issued: \\ November 3, 2016}

\section{Certificate Verification Key: 04EC-9117-AF29-C56C-950F}

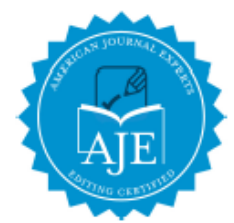

This certificate may be verified at www.aje.com/certificate. This document certifies that the manuscript listed above was edited for proper English language, grammar, punctuation, spelling, and overall style by one or more of the highly qualified native English speaking editors at American Journal Experts. Neither the research content nor the authors' intentions were altered in any way during the editing process. Documents receiving this certification should be English-ready for publication; however, the author has the ability to accept or reject our suggestions and changes. To verify the final AJE edited version, please visit our verification page. If you have any questions or concerns about this edited document, please contact American Journal Experts at support@aje.com 


\section{Manuscript \#MOLN-D-17-00041.}

Title:

\section{Major Points}

1. Some of the parameter is difficult to be understood. Firstly, why the tau protein in young SED is higher than all other group including young ATHL and old SED which seemed to be in opposite population. This data suggested that ATHL has no effect with physical exercise.

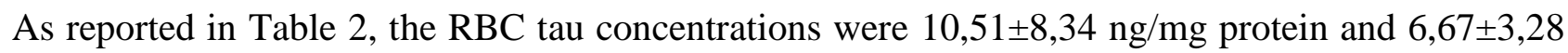
$\mathrm{ng} / \mathrm{mg}$ protein in young and old SED, respectively, suggesting that tau does not accumulate with age, at least in the analysed population. Consistent with these data, RBC levels of total tau significantly decreased with age in the total population (Fig. 4d, young versus older, $\mathrm{P}=0.0434$ ). Further studies will be needed to clarify the significance of tau decrease with age, also considering that literature data are not available for this parameter in RBCs.

Moreover, tau levels in RBCs were demonstrated to be almost the same levels in ATHL $(6,32 \pm 3,67$ $\mathrm{ng} / \mathrm{mg}$ protein and 5,59 $\pm 4,12 \mathrm{ng} / \mathrm{mg}$ protein in young and old ATHL, respectively). Based on these findings, it could be speculated that physical exercise can exert beneficial effects lowering tau concentration in particular in the young subgroup (see Figure 4d).

To clarify the data obtained on tau levels in RBCs, results and discussion concerning tau levels were modified in the text (see Results section, page 14, and Discussion section, page 22).

2. Correlation data showed in Fig $\mathbf{5}$ and Fig 6 lack some of the parameter/ Author should show all the correlation form each populations.

As required by the referee, all the correlations were added in the revised version of the manuscript (see the new Figures 5 and 6, and the new Supplementary Figures 1, 2 and 3). The data were omitted in the first version of the manuscript due to the lack of significant change in the parameters.

3. Authors detected misfolding proteins from RBC. Clarify whether excise could alter the RBC turnover that can effect on the expression of those proteins. Authors should measure the turnover of red blood cells and compared that between ATHL and SED groups. 
We thank the referee for his interesting comment. Intensive training could affect RBC turnover (Sports Med. 1995;19(1):9-31) and reduce RBC mass by intravascular hemolysis of senescent red blood cells. (Front Physiol. 2013; 4: 332). Actually, conflicting data have been emerging (Adv Clin Chem. 2013; 59:125-53; Int J Lab Hematol. 2011 Dec; 33(6):638-4; Acta Haematol. 2012;127(3):156-64), indicating that RBC production in athletes does not significantly differ from sedentary controls. Besides the actual effects of physical training, measuring RBC turnover in our cohort would require an ex novo recruitment of subjects and blood collection. For this reason, the influence of exercise on RBC ageing will be take into consideration in a future study. In the meantime, such criticism was discussed in the revised version of the manuscript (see Discussion section, page 23).

\section{The number of samples is too small to represent WB and immunoprecipitation figures. Authors should add samples more to make quantitative figures.}

Western blot analyses were conducted to qualitatively demonstrate that the analysed proteins (i.e. $\alpha$ syn, $A \beta, \alpha$-syn/A $\beta$, tau and $\alpha$-syn/tau) were expressed in RBCs (see Figure 1). Moreover, such assay was utilized to show the physical interaction in vitro of $\alpha$-syn with $\mathrm{A} \beta$ or tau (see Figure 2 ). In contrast, no comparison between groups was conducted using western blot data. In order to avoid misunderstanding, this issue was clarified in the revised version of the manuscript (see Methods section, page 6).

\section{Have authors ever tried to detect the level of those misfolding proteins to see whether they have any correlation of those expression in red blood cells.}

We thank the referee for his suggestion. In this paper, the levels of the oligomeric form of $\alpha$-syn were measured in RBCs. Unfortunately, no significant differences between SED and ATHL were found (see Figure 4B). As concern the other proteins, new specific antibodies and techniques have been emerging to detect oligomeric forms of tau (FASEB J 2012; 26(5): 1946-1959; Front Neurol. 2014; 5: 251) and A 3 (Cell Rep. 2014;7(1):261-8;J Neurosci. 2014 Feb 19;34(8):2884-97). We agree with the referee that measuring the misfolded forms of ND-related proteins will be an interesting point to assess the contribution of both oxidative stress and physical exercise, thus these points were added in the text as possible future goals (See Discussion section, page 23). 
6. In figure $1 \mathrm{~b}$, there are bands which do not indicate $\mathrm{A} \beta$ (middle panel: more than $25 \mathrm{kDa}$ ) or tau (lower panel: less than 50kDa). What do these bands mean?

Bands with a higher molecular weight than $25 \mathrm{kDa}$ (Fig. 1b, middle panel) could indicate elevated oligomeric form of A $\beta$ (JBC, 2015; 290: 17415-17438; PLoS One.2014;9:e114041). In contrast, bands lower than $50 \mathrm{kDa}$ (Fig. 1b, lower panel) have been related to truncated or cleaved forms of tau (Neuroscience Letters 2006; 399:106-110). Such findings were reported in the revised version of the manuscript (Results section, page 11).

7. In the result, the authors showed that hydroxyl TOSC values were inversely correlated with RBC total $\alpha$-syn in the ATHL subgroup. Is there any correlation between hydroxyl TOSC and total $\alpha$-syn concentration in SED group?

At P16 line3, authors concluded that $\alpha$-syn accumulation in RBCs is strongly related to hydroxyl AOC. There is no significant correlation between $\alpha$-syn concentration and hydroxyl AOC in young subgroup. Authors should try to discuss the discrepancy.

Any significant correlation between hydroxyl TOSC and total $\alpha$-syn concentration was found in SED group $\left(\mathrm{P}=0.223, \mathrm{R}^{2}=0.0097\right.$, new Suppl. Fig. 1a), although a trend toward an inverse correlation was evidenced. These findings were added in the revised version of the manuscript (Results section, page 16).

Since the correlation between hydroxyl TOSC and total $\alpha$-syn concentration was not found in the young subgroup, as well as in the SED cohort, the sentence reported at page 16 was modified. In particular, based on our results, a higher contribute of hydroxyl AOC on $\alpha$-syn accumulation can be speculated with advanced age or physical exercise (see Results section, page 16).

8. In figure 7, the authors should add the scatter plot of SED group. The scatter plot of hydroxyl TOSC vs $\alpha$-syn/A $\beta$ levels of the SED group was added in the manuscript (see new Figure $7 \mathrm{e})$.

In figure 8, the authors should add the scatter plot of all groups (Older, Young, ATHL, SED group). The scatter plots of hydroxyl TOSC vs $\alpha$-syn/tau levels of the missing groups were added in the manuscript (see new Figure 8d and e, and new Suppl. Fig. 4). 
In figure 9, the authors should add the plot of all groups (Older, Young group) about all proteins. The scatter plot of all the groups were added in the new version of the manuscript (see new Supplementary Figures 5-7).

\section{Minor Points}

1. Authors mistake numerical display in Table 1 and 2. For example, 37,50. Numerical display in Table 1 and 2 were corrected. Thank you.

2. "e4 allele" in figure legend (P25-Line27) should be " $\varepsilon 4$ allele." The figure legend was corrected. Thank you.

3. "e4 allele" in figure legend(P26-Line2) should be " $\varepsilon 4$ allele." The figure legend was corrected. Thank you.

4. Authors mentioned they used $A \beta$ antibody in section "Co-immunoprecipitationwestern blotting". However, they showed A 1-42 in Fig1. Which is correct? A $\beta$ antibody in section "Co-immunoprecipitation-western blotting" was corrected in A $\beta 1-42$. 
$\alpha$-synuclein aggregates with $\beta$-amyloid or tau in human red blood cells: correlation with antioxidant capability and physical exercise in human healthy subjects

Simona Daniele ${ }^{1 \#}$, Deborah Pietrobono ${ }^{1 \#}$, Jonathan Fusi ${ }^{2 \#}$, Caterina Iofrida ${ }^{1}$, Lucia Chico $^{2}$, Lucia Petrozzi $^{2}$, Annalisa Lo Gerfo ${ }^{2}$, Filippo Baldacci ${ }^{2}$, Fabio Galetta ${ }^{2}$, Gabriele Siciliano ${ }^{2}$, Ubaldo Bonuccelli $^{2}$, Gino Santoro ${ }^{2}$, Maria Letizia Trincavelli ${ }^{*}{ }^{*}$, Ferdinando Franzoni ${ }^{2 *}$, Claudia Martini ${ }^{1}$.

${ }^{1}$ Department of Pharmacy, University of Pisa, 56126 Pisa, Italy.

${ }^{2}$ Department of Clinical and Experimental Medicine, University of Pisa, 56120 Pisa, Italy.

\# These authors equally contributed to this work.

* Corresponding authors: Department of Pharmacy, University of Pisa, Via Bonanno 6, 56126 Pisa, Italy, and Department of Clinical and Experimental Medicine, University of Pisa, Via Savi 10, 56100, Pisa, Italy. E-mail addresses: maria.trincavelli@unipi.it; ferdinando.franzoni@unipi.it. 


\begin{abstract}
Neurodegenerative disorders (NDs) are characterized by abnormal accumulation/misfolding of specific proteins, primarily $\alpha$-synuclein ( $\alpha$-syn), $\beta$-amyloid - $-42_{2}(\mathrm{~A} \beta)$ and tau, in both brain and peripheral tissue. In addition to homo-oligomers, the role of $\alpha$-syn interactions with $\mathrm{A} \beta$ or tau has gradually emerged. The altered protein accumulation has been related to both oxidative stress and physical activity; nevertheless, no correlation among the presence of peripheral $\alpha$-syn heteroaggregates, antioxidant capacity and physical exercise has been discovered as of yet.

Herein, the content of $\alpha$-syn, $A \beta$, tau and of their heterocomplexes was determined in red blood cells (RBCs) of healthy subjects (sedentary and athletes). Such parameters were related to the extent of the antioxidant capability (AOC), a key marker of oxidative stress in aging-related pathologies, and to physical exercise, which is known to play an important preventive role in NDs and to modulate oxidative stress.

Tau content and plasma AOC toward hydroxyl radicals were both reduced in older or sedentary subjects; in contrast, $\alpha$-syn and $\mathrm{A} \beta$ accumulated in elderly subjects and showed an inverse correlation with both hydroxyl AOC and the level of physical activity. For the first time, $\alpha$-syn heterocomplexes with $A \beta$ or tau were quantified and demonstrated to be inversely related to hydroxyl AOC. Furthermore, $\alpha$-syn/A $\beta$ aggregates were significantly reduced in athletes and inversely correlated with physical activity level, independent of age.

The positive correlation between antioxidant capability/physical activity and reduced protein accumulation was confirmed by these data, and suggest that peripheral $\alpha$-syn heterocomplexes may represent new indicators of ND-related protein misfolding.
\end{abstract}

Key words: protein misfolding; neurodegenerative diseases; $\alpha$-synuclein; $\beta$-amyloid; tau; $\alpha$ synuclein heterocomplexes; antioxidant capability; physical exercise. 


\section{Introduction}

Neurodegenerative disorders (NDs), such as Alzheimer's disease (AD), Parkinson's disease (PD) and amyotrophic lateral sclerosis, are characterized by the pathological evidence of progressive neuronal loss in specific vulnerable areas [1-3] and reactive gliosis [4, 5], in which self-aggregating misfolded proteins form high-ordered insoluble fibrils in neurons and/or glial cells [4-6]. For example, abnormal accumulation of $\alpha$-synuclein ( $\alpha$-syn) has been established to form Lewy bodies and neurites in PD and dementia with Lewy bodies (DLB), as well as glial cytoplasmic inclusions in multiple system atrophy [7]. In contrast, the neuropathological hallmarks of AD are represented by senile plaques containing extracellular deposits of $\beta$-amyloid 1-42 $_{2}(\mathrm{~A} \beta)$ and by intra-neuronal neurofibrillary tangles composed of hyperphosphorylated tau protein [8, 9]. However, postmortem evaluation often discloses a mixed pattern of proteinopathies, commonly accompanied by signs of chronic cerebrovascular disease pathology. In this regard, the potential contribution of $\alpha$-syn to AD pathogenesis is emerging as well [10,11], with 30-40 \% of AD cases presenting Lewy bodies and Lewy neurites [12].

Data from the literature suggest that $A \beta$, tau and $\alpha$-syn might promote the accumulation or aggregation of one another [13]. Furthermore, in addition to homo-oligomers, the role of heterocomplexes has been emerging; $A \beta$ and $\alpha$-syn have been shown to co-immunoprecipitate and form complexes in patient brains and transgenic models, providing clear evidence for their direct interaction [14, 15]. Additionally, in different cellular systems, $\alpha$-syn has been demonstrated to bind to tau directly and promote the polymerization of the latter [13, 16-18], even in the axonal compartment [19]. Of note, the alterations in protein misfolding related to NDs are not restricted within the brain, but appear in peripheral tissue as well. For this reason, great efforts have been devoted to exploiting substantial biological changes and putative biomarkers in tissue other than the brain or cerebrospinal fluid (CSF) [20-24]. In this respect, the use of blood has gradually emerged due to its availability, low cost and time effectiveness [25].

ND-protein oligomerization has been linked not only to genetic factors but also to environmental factors [26, 27], primarily including oxidative stress [26, 28], which arises from an imbalance between an excessive generation of reactive oxygen species (ROS) and the biological system's capability to eliminate the reactive intermediates [29]. Oxidative stress leads to a progressive decline in cell physiology [30] by damaging cellular macromolecular components such as DNA, lipids and proteins $[31,32]$. As oxidative stress strongly contributes to abnormal protein misfolding and the propagation of oligomers, antioxidant therapies are emerging as a preventive therapeutic option for age-related NDs [33, 34]. 
Epidemiological studies have extensively demonstrated that regular exercise is an important preventive and therapeutic tool in AD, PD and cerebrovascular diseases [35]. The adaptive response to regular exercise involves the up-regulation of the enzymatic antioxidant system and modulation of oxidative damage, which culminates in a recovered redox state of brain cells [36, 37]. In addition to a reduction in oxidative damage, the effects of exercise seem to be quite intricate, including an increase in neurogenesis and capillarization and an enhanced proteolytic degradation of toxic oligomers by proteasomes and neprilysin [38-40]. In a recent paper, voluntary running has been shown to counteract amyloid deposition, tau phosphorylation, inflammatory reaction, and memory loss in a mouse model of $\mathrm{AD}$ [41]. Moreover, lower $\mathrm{A} \beta$ plasma concentrations and brain depositions have been observed in humans performing higher levels of physical activity [42], consistent with the hypothesis that exercise may be involved in the modulation of pathogenic changes associated with NDs [43].

All together, these data highlight the link between neurodegeneration, oxidative stress and physical exercise. However, the correlation among antioxidant capability, physical exercise and the accumulation of $\alpha$-syn heterocomplexes with tau and $\mathrm{A} \beta$ at a peripheral level has never been investigated. The aim of the current study was to examine how the levels of protein aggregates, associated with ND development, could be influenced by the intrinsic plasma antioxidant capacity and by physical activity. More specifically, plasma antioxidant capability (AOC), the primary marker of oxidative stress in aging-related pathologies [44], was measured in a cohort of young and older athletes and sedentary subjects, and related to the grade of physical exercise. Moreover, the content of total and oligomeric $\alpha$-syn, tau and $\mathrm{A} \beta$ was revealed in red blood cells (RBCs) of the same subjects. Indeed, these cells represent a good model to study the aging-related biochemical alterations, including protein misfolding [42, 45, 46]. Furthermore, $\alpha$-syn heterocomplexes with A $\beta$ or tau were detected and quantitatively measured to unveil their presence and putative role as novel indicator of oxidative stress-related neurodegeneration in peripheral fluids. 


\section{Materials and Methods}

Ascorbic acid, 2,20-azo-bisamidinopropane (ABAP), Iron (III) chloride hexa-hydrate, KMBA (acheto-g-(methylthiol)butyric acid) and recombinant human $\alpha$-syn, tau and A $\beta$ were purchased from Sigma Chemical Co. (St. Louis,MO, USA). Antibodies to $\alpha$-syn, tau and A $\beta$ were from Santa Cruz Biotechnology.

\section{Study population and setting of the study}

Forty-eight sex-matched endurance athletes (ATHL, mean age 44.6 \pm 13.4 years, range 22-74 years) recruited from the Sport Medicine Unit of the Department of Clinical and Experimental Medicine of the University of Pisa, and 58 healthy age-sex-matched sedentary volunteers (SED, mean age 46.7 \pm 14.5 years, range 20-75 years) were studied (Table 1). Athletes performed endurance exercise more than three times/week and were active in national road-running races.

All subjects were free of cardiovascular disease or other major medical disorders, as assessed by clinical history, physical examination, basal and stress electrocardiography, blood chemistry, hematology and urine analysis. Major criteria for inclusion of subjects in the trial were as followed: total plasma cholesterol ranging from 3.1 to $5.8 \mathrm{mmol} / \mathrm{L}$, HDL cholesterol from 0.67 to $1.9 \mathrm{mmol} / \mathrm{L}$, plasma triglycerides from 0.34 to $1.7 \mathrm{mmol} / \mathrm{L}$, body mass index lower than $30 \mathrm{~kg} / \mathrm{m}^{2}$, diastolic arterial blood pressure lower than $90 \mathrm{mmHg}$ and systolic arterial blood pressure lower than 140 $\mathrm{mmHg}$. Subjects were excluded if they had smoking habits or received any drug treatment within the previous two months.

Aerobic fitness was evaluated with a maximal graded cycle ergometry test performed by a cardiologist blinded to the other data. Participants started at 25 Watts. Increments of 25 watts per 2 min were made until exhaustion or until reaching one of the American College of Sports Medicine established criteria for maximal oxygen uptake [47]. Heart rate was continuously measured by ECG. Blood pressure and the rate of perceived exertion (RPE) were assessed at the end of each step. Recovery was monitored until heart rate was $<100 \mathrm{bpm}$. The maximum achieved resistance (Watts) was retained for all calculations. The 15-point Borg RPE scale [48, 49] was used to evaluate the level of intensity for each participant. The scale ranges from 6 to 20, with 6 corresponding to no exertion at all, 7.5 to extremely light, 9 to very light, 11 to light, 13 to somewhat hard, 15 to hard, 17 to very hard, 19 to extremely hard, and 20 to maximal exertion.

Each group was divided into a younger ( $<50$ years) and an older ( $>50$ years) subgroup (Table 1$)$. The time period between the last exercise bout and blood sampling was at least 48 hours.

This study was approved by the Ethics Committee of the Great North West Area of Tuscany (271/2014 to F.F.) and it was carried out in accordance with the Declaration of Helsinki. All 
subjects gave informed consent to participate in the study. Fully informed consent was obtained from each subject entering the study.

AOC was measured in plasma samples from the aforementioned cohort. RBCs were collected to quantify the content of total and oligomeric $\alpha$-syn, tau, A $\beta$ and $\alpha$-syn heterocomplexes with $A \beta$ or tau.

\section{Plasma and RBC collection.}

Whole blood was collected from healthy volunteers $(\mathrm{N}=106$, Table 1) into a tube containing EDTA as an anticoagulant. RBCs were separated from plasma by a centrifugation at $200 \times \mathrm{g}$ at $4{ }^{\circ} \mathrm{C}$ for 10 minutes. The plasma was then stored at $-80^{\circ} \mathrm{C}$ in different aliquots. The RBC pellet was centrifuged at $1000 \mathrm{x}$ g for $10 \mathrm{~min}$ and washed three times with PBS. RBC pellet was frozen at $-20^{\circ} \mathrm{C}$ until use.

\section{Co-immunoprecipitation-western blotting}

In order to verify $\alpha$-syn, tau and $\mathrm{A} \beta$ expression in human blood, RBCs (50 mg) were lysed with RIPA buffer [50] and then resolved by SDS-PAGE (8.5\%). Samples were probed overnight at $4^{\circ} \mathrm{C}$ with primary antibodies to $\alpha$-syn ( $\alpha / \beta$-synuclein N-19, SC-7012, Santa Cruz Biotechnology), tau (H-150 SC-5587, Santa Cruz Biotechnology) or A $\beta_{1-42}$ ( $\beta$-amyloid H-43 SC-9129, Santa Cruz Biotechnology). The primary antibodies were detected using peroxidase- conjugated secondary antibodies and a chemioluminescent substrate (ECL, Perkin Elmer).

To confirm the presence of $\alpha$-syn heterocomplexes with tau or $A \beta$, a co-immunoprecipitation assay was employed [50]. Briefly, $1 \mathrm{mg}$ of lysates obtained from RBCs was resuspended in RIPA buffer and was probed overnight under constant rotation with an anti- $\alpha$-syn antibody ( $5 \mu \mathrm{g} / \mathrm{sample})$, and then immunoprecipitated with protein A-Sepharose. After extensive washing, the immunocomplexes were resuspended in Laemmli solution, resolved by SDS-PAGE and probed overnight with primary antibodies to $\alpha$-syn (input), tau or $A \beta_{1-42}$ as described above.

Of note, western blot analyses were used as qualitative data on ND-related protein expression in RBCs.

\section{Immunoassay methods for total $\alpha$-synuclein}

Total $\alpha$-synuclein was detected in RBCs following literature's protocols [51]. Briefly, wells were pre-coated overnight at $4^{\circ} \mathrm{C}$ with a full length polyclonal antibody to $\alpha$-syn (sc-10717, Santa Cruz Biotechnology), and non-specific sites were blocked using bovine serum albumine (BSA) for $1 \mathrm{~h}$ at $37^{\circ} \mathrm{C}$. RBCs $(0,150 \mathrm{mg} / 100 \mu \mathrm{l})$ were captured on wells for $2 \mathrm{~h}$ at $25^{\circ} \mathrm{C}$. Purified recombinant protein standards of $\alpha$-syn were assayed in parallel with human samples to generate a standard curve. After 
extensive washing, samples were probed with a mouse monoclonal antibody to $\alpha$-syn (Santa Cruz, sc-12767), and subsequently with an anti-mouse-HRP antibody. The wells were then washed 4 times with PBS-T (phosphate buffered saline containing 0.01\% Tween 20), before adding the enzyme substrate TMB (3,3',5,5'-tetramethylbenzidine, Thermo Scientific) and leaving the colour to develop for $30 \mathrm{~min}$ at room temperature. Absorbance values at $450 \mathrm{~nm}$.

\section{Preparation of aged solutions of $\alpha$-syn and of the $\alpha$-syn biotinylated antibody}

Recombinant $\alpha$-syn were incubated in parafilm-sealed tubes at $37^{\circ} \mathrm{C}$ for 4 days in an Eppendorf Thermomixer with continuous mixing (1000 rpm), as reported previously [52].

To prepare the $\alpha$-syn biotinylated antibody, Sulfo-NHS-LC-Biotin (Pierce, Rockford, IL, USA) (200 mg) was reacted with the 211 mouse monoclonal antibody (mAb) (Santa Cruz Biotechnology, Santa Cruz, CA, USA) [53]. The mixture was desalted on Bio-Spin-6 columns (BIO-RAD, UK) to remove excess uncoupled biotin.

\section{Detection of oligomeric $\alpha$-syn}

Oligomeric $\alpha$-syn levels in RBCs were measured using an immunoenzymatic assay, as previously described [51, 52]. The plate was pre-coated overnight at room temperature with the mouse monoclonal $\alpha$-syn 211 antibody (Santa Cruz, sc-12767). After extensive washing with PBS-T, nonspecific sites were blocked with $1 \%$ BSA. RBCs $(0,04 \mathrm{mg} / 100 \mu \mathrm{l})$ were added to each well and incubated at $25^{\circ} \mathrm{C}$ for $2 \mathrm{~h}$. $\alpha$-syn oligomers were detected using the $\alpha$-syn biotinylated antibody, which recognizes amino acid residues 121-125 of human $\alpha$-syn. Whereas for antigen detection, streptavidin-horseradish peroxidase conjugate antibody (1:1000, GE Healthcare) was used. The wells were washed three times with PBS-T, before the addition of $100 \mu 1 /$ well of TMB, as reported above.

\section{Detection of total $A \beta$}

$\mathrm{A} \beta$ levels in blood samples were measured using an immuno-enzymatic assay, as described previously [53]. The plate was pre-coated overnight at $4^{\circ} \mathrm{C}$ with a specific antibody to A $\beta$ (Santa Cruz, sc-9129). After extensive washing with PBS-T, non-specific sites were blocked with $1 \%$ BSA. RBCs $(0,2 \mathrm{mg} / 100 \mu \mathrm{l})$ were added to each well and incubated at $25^{\circ} \mathrm{C}$ for one hour. After extensive washing with PBS-T, samples were detected using the polyclonal antibody to A $\beta$ (sc5399, Santa Cruz Biotechnology). The standard curve was constructed using recombinant human $\mathrm{A} \beta$ solutions at eight different concentrations. 


\section{Detection of total tau}

Tau levels in blood samples were measured using an immuno-enzymatic assay, as described previously [53]. The plate was pre-coated overnight at $4^{\circ} \mathrm{C}$ with a specific antibody to tau (Santa Cruz, sc-32274). After extensive washing with PBS-T, non-specific sites were blocked with $1 \%$ BSA. RBCs $(0,5 \mathrm{mg} / 100 \mu \mathrm{l})$ were added to each well and incubated at $25^{\circ} \mathrm{C}$ for one hour. After extensive washing with PBS-T, samples were detected using the polyclonal antibody to tau (sc5587, Santa Cruz Biotechnology). The standard curve was constructed using recombinant human tau solutions at eight different concentrations.

\section{Immunoassay detection of $\alpha$-syn/A $\beta$ heterocomplexes}

For the quantification of $\alpha$-syn/A $\beta$ interactions, a 'home-made' method was developed employing a "sandwich" immunoenzymatic assay [54, 55], as follows. Standard $\alpha$-syn/A $\beta$ were prepared by incubating $1 \mathrm{mg}$ of each protein, diluited in $2 \mathrm{mM}$ sodium dodecyl sulfate (SDS) in parafilm-sealed tubes at $37^{\circ} \mathrm{C}$ for $36 \mathrm{~h}$ in an "Eppendorf Thermomixer" with continuous mixing (500 rpm) [14]. Eight different dilutions of $\alpha$-syn/A $\beta$ were prepared; following capturing on wells pre-coated with a specific antibody to $A \beta$ (see below), the samples were collected, and $\alpha$-syn levels (i.e., the quotes of recombinant $\alpha$-syn not bound to $A \beta$ ) were quantified by a validated immunoenzymatic assay described above.

The microplate was pre-coated overnight at room temperature with $\beta$-amyloid $\mathrm{H}-43$ antibody (1:100, sc-9129, Santa Cruz Biotechnology) in poli-L-ornithine/ $\mathrm{NaHCO}_{3}, \mathrm{pH}$ 9.6. After two washes with PBS-T, RBCs (40 mg/sample in $2 \mathrm{mM} \mathrm{SDS}$ ) were added to each well and incubated at $25^{\circ} \mathrm{C}$ for $2 \mathrm{~h}$. The wells were washed, and non-specific sites were blocked with $1 \%$ BSA for 30 min at $37^{\circ} \mathrm{C}$. To detect $\alpha$-syn bound to $\mathrm{A} \beta$, samples were probed for $2 \mathrm{~h} 37^{\circ} \mathrm{C}$ with a specific antibody to $\alpha$-syn (sc-12767, Santa Cruz Biotechnology), and subsequently with the appropriate HRPconjugated antibody. After $1.5 \mathrm{~h}$, the wells were washed twice with PBS-T, before the addition of $100 \mu \mathrm{l} /$ well of TMB. Absorbance was measured at $450 \mathrm{~nm}$. Relative concentration of $\alpha$-syn/A $\beta$ complexes were calculated according to the standard curve obtained in each microplate. The assays of blood plasma were all carried out in duplicate. Blood samples from athletes and sedentary subjects were analysed together in batch runs. For some subjects, multiple assays were performed on diluted RBCs from a single subject to confirm that low or high concentrations were in the linear range of the assay. All measurements were repeated twice and the average value was determined.

\section{Immunoassay detection of $\alpha$-syn/tau heterocomplexes}


For the quantification of $\alpha$-syn/tau interactions, a similar 'home-made' method was developed (see the precedent paragraph). Standard $\alpha$-syn/tau were prepared by incubating $1 \mathrm{mg}$ of each protein, diluted in $2 \mathrm{mM}$ SDS in parafilm-sealed tubes at $37^{\circ} \mathrm{C}$ for $1 \mathrm{~h}$ in an Eppendorf Thermomixer with continuous mixing $(500 \mathrm{rpm})$. Following capturing on wells pre-coated with a specific antibody to $\alpha$-syn (see below), the samples were collected, and tau levels (i.e., the quotes of recombinant $\alpha$-syn not bound to $A \beta$ ) were quantified by a validated immunoenzymatic assay described above.

The microplate was pre-coated overnight at room temperature with anti- $\alpha$-syn antibody $(1: 100$, sc7012, Santa Cruz Biotechnology) in poli-L-ornithine/ $\mathrm{NaHCO}_{3}, \mathrm{pH}$ 9.6. After two washes with PBST, RBCs ( $80 \mathrm{mg} / \mathrm{sample}$ in $2 \mathrm{mM} \mathrm{SDS}$ ) were added to each well and incubated at $25^{\circ} \mathrm{C}$ for $2 \mathrm{~h}$. The wells were washed, and non-specific sites were blocked with $1 \% \mathrm{BSA}$ for $30 \mathrm{~min}$ at $37^{\circ} \mathrm{C}$. To detect $\alpha$-syn bound to tau, samples were probed for $2 \mathrm{~h} 37^{\circ} \mathrm{C}$ with a specific antibody to tau (sc5587, Santa Cruz Biotechnology), and subsequently with the appropriate HRP-conjugated antibody. After $1.5 \mathrm{~h}$, the wells were washed twice with PBS-T, before the addition of $100 \mu \mathrm{l} /$ well of TMB. Absorbance was measured at $450 \mathrm{~nm}$. Relative concentration of $\alpha$-syn/tau complexes were calculated according to the standard curve obtained in each microplate.

\section{Total Oxyradical Scavenging Capacity (TOSC) Assay}

The plasma antioxidant capability (AOC) was assessed by the TOSC assay, a gas chromatographic assay for determining oxyradical scavenging capacity of biological fluids $[56,57]$. Peroxyl radicals were generated by thermal homolysis of $20 \mathrm{mM} \mathrm{ABAP}$ at $35^{\circ} \mathrm{C}$ in $100 \mathrm{mM}$ potassium phosphate buffer, $\mathrm{pH}$ 7.4. Hydroxyl radicals were generated at $35^{\circ} \mathrm{C}$ by the iron plus ascorbate-driven Fenton reaction (1.8 mM Fe3+, $3.6 \mathrm{mM}$ EDTA, and $180 \mathrm{mM}$ ascorbic acid in $100 \mathrm{mM}$ potassium phosphate buffer, $\mathrm{pH}$ 7.4). Reactions with $0.2 \mathrm{mM}$ KMBA were carried out in $10 \mathrm{ml}$ vials sealed with gas-tight Mininert1 valves (Supelco, Bellefonte, PA) in a final volume of $1 \mathrm{ml}$.

Ethylene production was measured by gas-chromatographic analysis of $200 \mu \mathrm{l}$ aliquots taken from the headspace of vials at timed intervals during the course of the reaction. Analyses were performed with a Hewlett-Packard gas chromatograph (HP 7820A Series, Andoven, MA) equipped with a Supelco DB-1 (30 x 0.32 × $0.25 \mathrm{~mm}$ ) capillary column and a flame ionization detector (FID). The oven, injection and FID temperatures were respectively 35,160 and $220^{\circ} \mathrm{C}$. Hydrogen was the carrier gas (flow rate of $1 \mathrm{ml} / \mathrm{min}$ ) and a split ratio of 20:1 was used. Total ethylene formation was quantified from the area under the kinetic curves that best define the experimental points obtained for control reactions and after addition of plasma during the reaction [56-58]. TOSC values were quantified from the equation TOSC $=100-($ SA/CA x 100), where SA and CA are respectively the area under the curve (AUC) for sample and control reaction. A TOSC value of 0 corresponds to a 
sample with no scavenging capacity. A TOSC value of 100 is attributed to a compound that entirely suppresses the ethylene formation whereas a pro-oxidant compound shows a negative TOSC value [59]. Consequently, antioxidants and pro-oxidants molecules can be distinguished by the obtained results. The linearity of dose-response curve between plasma $(\mathrm{ml})$ and the antioxidant response (TOSC value) was tested and good correlation coefficients (generally greater than 0.9) were obtained at the different doses used to test the validity of our experiments. Each experiment was performed in duplicate to account for the intrinsic variability of the method. The results obtained with plasma were expressed in TOSC units. In our hands, the coefficient of variation $(\mathrm{CV})$ of the method ranged between $2 \%$ and $5 \%[57,60]$.

\section{Genotyping}

Apolipoprotein E (Apo E) genotypes were identified by restriction fragment length polymorphism (RFLP), using genomic DNA extracted from blood of heatlhy subjects ( $\mathrm{N}=87$, Table 1). PCR was performed using 1.5 pmol of each primer (forward: 5 ' -TCG-GCCGCA-GGG-CGC-TGA-TGG-3 ' and reverse: 5 ' -CTCGCG-GGC-CCC-GGC-CTG-GTA-3 '), $250 \mu \mathrm{mol} / \mathrm{l} \mathrm{dNTPs,} \mathrm{Buffer} \mathrm{10X,} 25$ $\mathrm{mM} \mathrm{MgCl}_{2}$, GC-Rich (10\% of the final volume), 2 Units of Taq DNA polymerase (Applied Biosystems Inc., Branchburg, NJ), and $10 \mathrm{ng} / \mu \mathrm{l}$ of genomic DNA. Reactions were performed in a Perkin Elmer thermal cycler for one cycle at $94{ }^{\circ} \mathrm{C}$ for $6 \mathrm{~min}, 30$ cycles at $94{ }^{\circ} \mathrm{C}$ for $40 \mathrm{~s}, 67{ }^{\circ} \mathrm{C}$ for $30 \mathrm{~s}, 72{ }^{\circ} \mathrm{C}$ for $45 \mathrm{~s}$, and a final extension at $72{ }^{\circ} \mathrm{C}$ for $5 \mathrm{~min}$. The amplified fragments, after digestion with $3 \mathrm{U}$ of HhaI restriction enzyme, were separated using 5\% agarose gel electrophoresis, and the restriction patterns were visualized by ethidium bromide staining and UV light. The genotypes of a group of patients were confirmed by ABI PRISM 310 Automated Sequencer (Applied Biosystems, Forster City, CA, USA).

\section{Statistical analysis}

Data are presented as mean value \pm SD. The population included in this study presented a normal distribution for age. Differences between groups were evaluated by one-way analysis of variance (ANOVA). When only two groups were present, unpaired t test was used. Correlation between variables was determined by linear regression analysis, while interactions between variables were calculated by correlation and multiple regression analyses. Covariate analysis was performed by ztest. All statistical procedures were performed using the StatView program (Abacus Concepts, Inc., SAS Institute, Cary, NC) [58]. 


\section{Results}

\section{Descriptive analysis}

The clinical characteristics of the total cohort and of the four subgroups (young SED, young ATHL, older SED and older ATHL) are reported in Table 1. The young and older cohort presented a mean age of 35.5 \pm 9.6 and $60.4 \pm 6.9$, respectively. The ATHL and SED groups did not present significant differences in body mass index (BMI) and age. As expected, the ATHL group presented a lower resting heart rate than the SED group $(\mathrm{P}<0.001)$. The level of physical activity was significantly higher in the ATHL group than the SED group in the total cohort as well as in young and older subjects.

When the cohort was stratified based on APOE e4 allele carriage (see below), there were 14 carriers of the allele (8 SED and 4 ATHL).

\section{Expression of $\alpha$-syn, tau, $A \beta$ and of $\alpha$-syn heterocomplexes with tau or $A \beta$ in red blood cells: immunoblotting analysis}

First, the presence of $\alpha$-syn, tau and $\mathrm{A} \beta$ in RBCs was assessed by western blotting analysis. As depicted in Figure 1a, in RBCs, the anti- $\alpha$-syn antibody recognized $15 \mathrm{kDa}$ and $30 \mathrm{kDa}$ proteins, corresponding to $\alpha$-syn [61], whereas the anti-A $\beta$ antibody labelled 5 and $15 \mathrm{kDa}$ proteins (Fig. 1a), corresponding to $\mathrm{A} \beta$ monomeric and oligomer forms, respectively [62,63]. Bands with a higher molecular weight than $25 \mathrm{kDa}$ (Fig. $1 \mathrm{~b}$, middle panel) could indicate elevated oligomeric form of $\mathrm{A} \beta$ $[64,65]$. These data confirm that RBCs expressed detectable levels of $\alpha$-syn and A $\beta$, consistent with data from the literature $[45,66]$. Finally, the anti-tau antibody produced the characteristic triplet bands ranging between 55 and $74 \mathrm{kDa}$ [67], together with an additional band, demonstrating that RBCs express the tau protein as well (Fig. 1a). Of note, bands lower than $50 \mathrm{kDa}$ (Fig. 1b, lower panel have been related to truncated or cleaved forms of tau containing the $\mathrm{C}$-terminal region [68].

Then, the presence of $\alpha$-syn heterocomplexes in blood cells was verified using a coimmunoprecipitation-western blotting assay (Fig. 1b). To this purpose, cell lysates were immunoprecipitated using an anti- $\alpha$-syn antibody and then immunoblotted with an anti-tau or anti$\mathrm{A} \beta$ antibody. In parallel, lysates were also immunoprecipitated using an anti- $\alpha$-syn antibody and immunoblotted with the same antibody. In $\alpha$-syn immunoprecipitates obtained from RBCs (Fig. 1b, upper panel), the anti- $\alpha$-syn antibody recognized $15 \mathrm{kDa}$ and $30 \mathrm{kDa}$ proteins that corresponded to 
$\alpha$-syn protein [61]. The A $\beta$ immunoblotting performed on $\alpha$-syn immunoprecipitates from RBCs (Fig. 1b, middle panel) showed several immunoreactive bands that corresponded to the monomeric and oligomeric A $\beta$ forms (Fig. 1b) [62]. Similar results were obtained probing $\alpha$-syn immunoprecipitates with an anti-tau antibody (Fig. 1b, bottom panel). Globally, the results demonstrated that $\alpha$-syn forms heterocomplexes with $\mathrm{A} \beta$ and tau at a peripheral level.

\section{Establishment of an immunoenzymatic assay to detect $\alpha$-syn/A $\beta$ heterocomplexes}

To confirm the qualitative results obtained in the co-immunoprecipitation-western blotting analysis and to quantitatively detect the levels of heterocomplexes in RBCs, an immunoenzymatic assay was developed and validated, as follows. Standard $\alpha$-syn/A $\beta$ heterocomplexes were prepared by incubating $1 \mathrm{mg}$ of each protein, prepared in $2 \mathrm{mM} \mathrm{SDS}$, in parafilm-sealed tubes at $37^{\circ} \mathrm{C}$ for $36 \mathrm{~h}$ with continuous mixing [14]. As depicted in Figure 2a (left panel), in $\alpha$-syn immunoprecipitates, the anti- $\alpha$-syn antibody recognized a $15 \mathrm{kDa}$ protein corresponding to $\alpha$-syn. In parallel, no significant labelling was detected in $\mathrm{A} \beta$ alone (Fig. 2a, left panel), confirming the specificity of the antibody immunoreactivity. The A $\beta$ immunoblotting performed on $\alpha$-syn immunoprecipitates revealed four immunoreactive bands (Fig. 2a, right panel) [62], demonstrating the induction of $\alpha-\operatorname{syn} / \mathrm{A} \beta$ heterocomplexes in vitro in our experimental conditions.

To set up the immunoenzymatic assay, eight different dilutions of $\alpha$-syn/A $\beta$ were prepared and captured on wells pre-coated with an antibody specific to $A \beta$; the subsequent use of an antibody specific to $\alpha$-syn and the appropriate HRP-conjugated antibody allowed for quantification of $\alpha$ syn/A $\beta$ (see Methods section for experimental details). The results (Fig. 2b) showed a concentration-dependent increase in the specific absorbance at $450 \mathrm{~nm}$, thus demonstrating the specificity and validity of the assay. The absorbance at $450 \mathrm{~nm}$ of blank wells obtained in the absence of the $\alpha$-syn primary antibody consistently remained under $20 \%$ of the total values (data not shown).

To determine the amount of recombinant $\alpha$-syn not bound to $A \beta$, different dilutions of recombinant $\alpha$-syn/A $\beta$ proteins were captured on wells pre-coated with an antibody specific to $A \beta$, as described above. Following incubation, the samples were collected, and $\alpha$-syn levels (i.e., recombinant $\alpha$-syn not bound to $A \beta$ ) were quantified by a validated immunoenzymatic assay. Such analyses revealed that in our experimental conditions (i.e., $2 \mathrm{mM}$ SDS for $36 \mathrm{~h}$ ), $85 \pm 2 \%$ of recombinant proteins formed $\alpha$-syn/A $\beta$ heterocomplexes (Fig. 2c). The corrected standard curve was then obtained by subtracting the amount of free $\alpha$-syn from the theoretical $\alpha$-syn/A $\beta$ concentrations (Fig. 2c) and further used to quantify such heterocomplexes in blood cells. 


\section{Establishment of an immunoenzymatic assay to detect $\alpha$-syn/tau heterocomplexes}

Standard $\alpha$-syn/tau complexes were prepared by incubating $1 \mathrm{mg}$ of each protein, prepared in $2 \mathrm{mM}$ SDS, in parafilm-sealed tubes at $37^{\circ} \mathrm{C}$ for $1 \mathrm{~h}$. The tau immunoblotting performed on $\alpha$-synimmunoprecipitates revealed specific immunoreactive bands (Fig. 3a, right panel, first line) that were not shown for recombinant tau alone (Fig. 3a, right panel, second line). These data demonstrate the induction of $\alpha$-syn/tau heterocomplexes in vitro in our experimental conditions.

Different dilutions of $\alpha$-syn/tau were prepared and captured on wells pre-coated with a specific antibody to $\alpha$-syn; the subsequent use of an antibody specific to tau and the appropriate HRPconjugated antibody allowed for quantification of $\alpha$-syn/tau. The results (Fig. 3b) showed a concentration-dependent increase in specific absorbance at $450 \mathrm{~nm}$, thus demonstrating the specificity and validity of the assay.

To determine the amount of recombinant $\alpha$-syn not bound to tau, different dilutions of recombinant $\alpha$-syn/tau proteins were captured on wells pre-coated with a specific antibody to $\alpha$-syn, as described above. Following incubation, the samples were collected, and tau levels (i.e., recombinant $\alpha$-syn not bound to $\alpha$-syn) were quantified by a validated immunoenzymatic assay. Such analyses revealed that in our experimental conditions (i.e., $2 \mathrm{mM}$ SDS for $1 \mathrm{~h}$ ), $78 \pm 7 \%$ of the recombinant proteins formed $\alpha$-syn/tau heterocomplexes (Fig. 3c). The corrected standard curve was then obtained by subtracting the theoretical $\alpha$-syn/tau concentrations from the amount of free $\alpha$-syn (Fig. 3c) and further used to quantify such heterocomplexes in blood cells.

\section{Total and oligomeric $\alpha$-syn concentrations in RBCs of healthy subjects}

Total and oligomeric $\alpha$-syn levels were quantitatively measured in RBCs isolated from 106 healthy subjects (Table 2). In the total cohort of healthy subjects (young versus older), no correlations were found between age and total or oligomeric $\alpha$-syn RBC concentrations (Fig. $4 \mathrm{a}$ and b, total $\alpha$-syn: $\mathrm{P}=0,4123$; oligomeric $\alpha$-syn: $\mathrm{P}=0,8993)$. In contrast, total $\alpha$-syn significantly decreased with age in the ATHL group (young ATHL versus older ATHL, Fig. 4a, P=0.0011), whereas an opposite trend was found in the SED group (young SED versus older SED, Fig. 4a, $\mathrm{P}=0.1376$ ).

As depicted in Figure 4 (panel a and b), total and oligomeric $\alpha$-syn in RBCs showed comparable values in the ATHL and SED groups, either in the total (total $\alpha$-syn: $\mathrm{P}=0.6284$, oligomeric $\alpha$-syn: $\mathrm{P}=0.5012$ ) or in the young population (young ATHL versus young $\mathrm{SED}$, total $\alpha$-syn: $\mathrm{P}=0.1683$, oligomeric $\alpha$-syn: $\mathrm{P}=0.9181$ ). Moreover, in the older cohort, oligomeric $\alpha$-syn was not significantly different between the ATHL and SED groups (Fig. 4b, $\mathrm{P}=0.1236$ ). In contrast, total $\alpha$-syn levels in 
RBCs were significantly lower in the elderly ATHL group compared to that in the elderly SED group (Fig. 4a, $\mathrm{P}=0.0007$ ), suggesting that physical activity may play a major role in modulating total $\alpha$-syn levels in RBCs with increasing age.

\section{$A \beta$ concentrations in RBCs of healthy subjects}

$\mathrm{A} \beta$ levels in RBCs (Table 2) were found to progressively accumulate with age in the SED population (young SED versus older $\mathrm{SED}, \mathrm{P}=0.0369$, Fig. 4c), whereas comparable values were found in the total (total young versus total older, $\mathrm{P}=0.5622$ ) and ATHL population (young ATHL versus older ATHL, $\mathrm{P}=0.2502$ ). Conversely, the analyzed parameter did not significantly differ between the ATHL and SED populations in the whole cohort (Fig. 4c, P=0.9407), as well as in the young subjects (young ATHL versus young SED, Fig. 4c, P=0.2987). Interestingly, as shown for total $\alpha$-syn, the ATHL group presented significantly lower levels of A $\beta$ in the older subgroup (older ATHL versus older SED, Fig. 4c, P=0.0360).

\section{Tau concentrations in RBCs of healthy subjects}

RBC levels of total tau significantly decreased with age in the total population (Fig. 4d, young versus older, $\mathrm{P}=0.0434)$; consistently, tau levels were significantly higher in the young SED population than in the older SED population (Fig. 4d, $\mathrm{P}=0.0202$ ), while they did not change with age in the ATHL group (young ATHL versus older ATHL, $\mathrm{P}=0.5382$ ).

Surprisingly, tau concentrations were significantly lower in the ATHL group than in the SED group in the total population (total ATHL versus total SED, Fig. 4d, $\mathrm{P}=0.0182$ ) and in the young cohort (young ATHL versus young SED, $\mathrm{P}=0.0343$ ) but not in the older one (older ATHL versus older $\mathrm{SED}, \mathrm{P}=0.2893$ ). These data suggest that $\mathrm{RBC}$ tau can exert beneficial effects especially in the young subgroup.

\section{$\alpha$-syn heterocomplexes with $\mathrm{A} \beta$ or tau in RBCs of healthy subjects}

Finally, $\alpha$-syn/A $\beta$ and $\alpha$-syn/tau heterocomplexes were measured in RBCs using the "home-made" immunoenzymatic assay. The results (Fig. 4e and f) showed that $\alpha$-syn/A $\beta$ or $\alpha$-syn/tau levels in RBCs did not differ between young and elderly subjects $(\mathrm{P}=0.3529$ and $\mathrm{P}=0.7145$, respectively). Consistently, such parameters were comparable between the young and older SED groups and between the young and older ATHL groups (Fig. 4e and f). 
Significantly lower concentrations of $\alpha$-syn/A $\beta$ were found in ATHL subjects than in SED subjects in the whole cohort $(\mathrm{P}=0.0001)$. This difference was also observed in the older subpopulation (older ATHL versus older SED, Fig. 4e, $\mathrm{P}=0.0055$ ) and in the young one (young ATHL versus young $\mathrm{SED}, \mathrm{P}=0.0038)$. These data suggest that $\alpha$-syn $/ \mathrm{A} \beta$ levels in $\mathrm{RBCs}$ are modulated by physical activity.

$\alpha$-syn/tau levels did not differ in young versus older subgroups (Fig. 4f and Table 2). Moreover, contrary to $\alpha$-syn/A $\beta$, no significance difference in $\alpha$-syn/tau concentrations (Fig. $4 \mathrm{f}$ ) was found between the SED and ATHL groups (whole cohort: $\mathrm{P}=0.8659$; older cohort: $\mathrm{P}=0.6021$; young cohort: $\mathrm{P}=0.8993)$. These results suggest that the interaction of $\alpha$-syn with tau is not modulated by physical exercise.

\section{Plasma antioxidant capacity (AOC) in healthy subjects}

The antioxidant capacity was measured in plasma from healthy subjects using the TOSC assay (Table 2); higher mean levels from this assay are related to a better antioxidant capability.

The results showed that AOC toward hydroxyl radicals was significantly higher in young subjects than in the elderly in the SED cohort (young SED vs older SED, $\mathrm{P}=0.0366$, Fig. 5a), thus confirming that AOC progressively decreases with age [69].

No differences in TOSC values toward hydroxyl or peroxyl radicals were obtained when comparing young versus older subjects of the total population (Total young vs Total older, hydroxyl: $\mathrm{P}=0.2511$; peroxyl: $\mathrm{P}=0.1640$, Fig. 5a and $\mathrm{b}$ ), and the young ATHL group showed significantly lower TOSC values toward hydroxyl than the older ATHL group (Fig. 5a, P=0.0019). These results suggest that additional factors other than age may influence AOC (see discussion section).

As expected, AOC toward hydroxyl (Fig. 5a) and peroxyl (Fig. 5b) radicals was significantly higher in the ATHL group than in the SED group in the whole cohort (Total ATHL vs Total SED, hydroxyl: $\mathrm{P}<0.0001$; peroxyl: $\mathrm{P}=0.0442$ ) and in the young subpopulation (Young ATHL versus young SED, hydroxyl: $\mathrm{P}=0.0362$; peroxyl: $\mathrm{P}=0.0434$, Fig. 5a and b). In the older subgroup (older ATHL versus older SED), a statistical significance was reached only for hydroxyl radicals (Fig. 5a and b, hydroxyl: $\mathrm{P}<0.0001$; peroxyl: $\mathrm{P}=0.5360$ ). These results confirm that physical activity is able to enhance antioxidant capacity in human subjects.

Consistent with these findings, hydroxyl TOSC values directly correlated with the level of physical activity in the whole subpopulation (Fig. 5c, $\mathrm{P}=0.0172, \mathrm{R}^{2}=0.131$ ) and in older subjects (Fig. 5d, $\mathrm{P}=0.0055, \mathrm{R}^{2}=0.373$ ) but not in young subjects (Fig. 5e, $\mathrm{P}=0.2352$ ). These data indicate that physical activity level can influence AOC, in particular against hydroxyl radicals. 
Interestingly, peroxyl TOSC values directly correlated with the physical activity level in the SED group $\left(\mathrm{P}=0.0188, \mathrm{R}^{2}=0.274\right.$, Fig. $\left.5 \mathrm{f}\right)$, suggesting that a low grade of physical activity can play a role in the antioxidant capability against peroxyl radicals.

\section{Correlation of ND-related proteins with plasma antioxidant capability}

Correlations between plasma AOC and $\alpha$-syn, A $\beta$, tau and $\alpha$-syn heterocomplexes were determined by linear regression analysis.

1) $\alpha$-syn: The total $\alpha$-syn concentration in RBCs was inversely correlated with hydroxyl AOC in the whole cohort (Fig. 6a, $\mathrm{P}=0.0006, \mathrm{R}^{2}=0.251$ ), as well as in the older subjects (Fig. 6b, $\mathrm{P}=0.0021$, $\mathrm{R}^{2}=0.435$ ) but not in young subjects (Suppl. Fig. 1a, $\mathrm{P}=0.2656$ ). Furthermore, hydroxyl TOSC values were inversely correlated with RBC total $\alpha$-syn in the ATHL subgroup (Fig. 6c, P=0.0004, $\left.\mathrm{R}^{2}=0.409\right)$. Any significant correlation between hydroxyl TOSC and total $\alpha$-syn concentration was found in SED group $\left(\mathrm{P}=0.223, \mathrm{R}^{2}=0.0097\right.$, Suppl. Fig. 1b). Based on these findings, a higher contribute of hydroxyl AOC on $\alpha$-syn accumulation can be speculated with advanced age or in pre presence of physical exercise.

In contrast, no correlation was found between the concentration of oligomeric $\alpha$-syn of RBCs and hydroxyl AOC in the whole cohort (Suppl. Fig. 1c, P=0.3874), the older subpopulation (Suppl. Fig. $1 \mathrm{~d}, \mathrm{P}=0.2961$ ), or in the young one (Suppl. Fig. 1e, $\mathrm{P}=0.9458$ ). These findings suggest that oligomeric $\alpha$-syn is poorly related to hydroxyl AOC.

In contrast to hydroxyl AOC, peroxyl radicals did not show any correlation with total $\alpha$-syn in the whole cohort (Suppl. Fig. 1f, P=0.4675), older subjects (Suppl. Fig. 1g, P=0.7630) or in the young ones (Suppl. Fig. 1h, $\mathrm{P}=0.5187$ ).

2) A $\beta$ : Peroxyl and hydroxyl TOSC values did not show any significant correlation with RBC A $\beta$ levels in the total cohort (Suppl. Fig. $2 \mathrm{a}$ and b, peroxyl: $\mathrm{P}=0.2550$; hydroxyl: $\mathrm{P}=0.197$ ) or in young subjects (Suppl. Fig. 2c and d, peroxyl: $\mathrm{P}=0.2550$; hydroxyl: $\mathrm{P}=0.197$ ). Similar results were obtained in the SED and ATHL populations (Suppl. Fig. 2e-h, peroxyl SED: P=0.3837; hydroxyl SED: $\mathrm{P}=0.3435$; peroxyl ATHL: $\mathrm{P}=0.7064$; hydroxyl ATHL: $\mathrm{P}=0.7635)$. Interestingly, $\mathrm{A} \beta$ levels were inversely correlated with AOC toward hydroxyl radicals in the elderly cohort only (Fig. 6d, $\mathrm{P}=0.0342, \mathrm{R}^{2}=0.266$ ), thus suggesting that $\mathrm{A} \beta$ levels are related to hydroxyl AOC with increasing age.

3) Tau: Peroxyl and hydroxyl TOSC values did not show any significant correlation with RBC tau levels, regardless of age (Suppl. Fig. 3a-f, total cohort, peroxyl: $\mathrm{P}=0.1563$; hydroxyl: $\mathrm{P}=0.1563$; young cohort: hydroxyl: $\mathrm{P}=0.5840$; peroxyl: $\mathrm{P}=0.5528$; older cohort, peroxyl: $\mathrm{P}=0.5943$; hydroxyl: 
$\mathrm{P}=0.1806$ ), although a trend toward an inverse correlation was evidenced. Interestingly, tau levels in RBCs were inversely related to hydroxyl but not peroxyl TOSC values in the ATHL group (hydroxyl: $\mathrm{P}=0.0497, \mathrm{R}^{2}=0.151$, Fig. 6e; peroxyl: $\mathrm{P}=0.5122$, Suppl. Fig. $3 \mathrm{~g}$ ).

4) $\alpha$-syn/A $\beta$ : Hydroxyl TOSC values were inversely correlated with $\alpha$-syn/A $\beta$ levels in the whole population (Fig. 7a, $\mathrm{P}=0.0002, \mathrm{R}^{2}=0.287$ ), older subjects (Fig. $7 \mathrm{~b}, \mathrm{P}=0.0239, \mathrm{R}^{2}=0.266$ ), and the young subpopulation (Fig. $7 \mathrm{c}, \mathrm{P}=0.0041, \mathrm{R}^{2}=0.318$ ), indicating that a higher plasma AOC toward hydroxyl radicals is associated with a lower concentration of $\alpha$-syn/A $\beta$ heterocomplexes. Similar data were found in the ATHL subgroup (Fig. 7d, $\mathrm{P}=0.0003, \mathrm{R}^{2}=0.428$ ), but not in SED (Fig. 7e, $\mathrm{P}=$ 1499). These data suggest that $\alpha$-syn/A $\beta$ accumulation is strongly associated with hydroxyl-related oxidative stress in RBCs.

No significant correlation between peroxyl TOSCA values and $\alpha$-syn/A $\beta$ levels was found, regardless of age (total population: $\mathrm{P}=0.5817$; young: $\mathrm{P}=0.8817$; older: $\mathrm{P}=0.4378$ ) or physical activity (ATHL: $\mathrm{P}=0.0951$; SED: $\mathrm{P}=0.1490$ ).

5) $\alpha$-syn/tau: An inverse correlation between $\alpha$-syn/tau concentration and hydroxyl TOSC values was demonstrated in the whole population (Fig. $8 \mathrm{a}, \mathrm{P}=0.0325, \mathrm{R}^{2}=0.107$ ), the older subpopulation (Fig. 8b, $\mathrm{P}=0.0478, \mathrm{R}^{2}=0.196$ ), and in the ATHL group (Fig. 8c, $\mathrm{P}=0.0478, \mathrm{R}^{2}=0.196$ ). No relationship was detected in the SED group (Fig. 8d, $\mathrm{P}=0.1338$ ) or in the young cohort (Fig. 8e, $\mathrm{P}=0.5548$ ). These findings suggest that the interaction of $\alpha$-syn with tau is modulated by hydroxyl AOC, particularly with increasing age and with a higher rate of physical exercise.

No correlation with TOSC against peroxyl radicals was detected, regardless of age (whole population: $\mathrm{P}=0.5968$; older cohort: $\mathrm{P}=0.8385$; young cohort: $\mathrm{P}=0.3640$, Suppl. Fig. $4 \mathrm{a}-\mathrm{c}$ ), or physical activity (ATHL: P=0.9618; SED: P=0.3458, Suppl. Fig. 4d-e).

\section{Correlation of ND-related proteins with the level of physical activity}

Correlations between the level of physical activity and $\alpha$-syn, A $\beta$, tau and $\alpha$-syn heterocomplexes were determined by linear regression analysis.

1) $\alpha$-syn: In RBCs of elderly subjects, both total and oligomeric $\alpha$-syn were inversely correlated with physical activity level, although a statistical significance was only observed for total $\alpha$-syn (Fig. 9a, total $\alpha$-syn: $\mathrm{P}=0.0463, \mathrm{R}^{2}=0.103$; Suppl. Fig. 5a, oligomeric $\alpha$-syn: $\mathrm{P}=0.1256$ ). In contrast, there was no significant correlation with the physical activity level in the total cohort (Suppl. Fig. 5b and c, total $\alpha$-syn: $\mathrm{P}=0.6950$; oligomeric $\alpha$-syn: $\mathrm{P}=0.4842$ ) or the young one (Suppl. Fig. 5d and e, total: $\mathrm{P}=0.5289$; oligomeric: $\mathrm{P}=0.9529)$. Moreover, any significant correlation was found in the ATHL group (Suppl. Fig. 5f and g, total $\alpha$-syn: $\mathrm{P}=0.8662$; oligomeric $\alpha$-syn: $\mathrm{P}=0.8217$ ). Interestingly, the grade of physical exercise was inversely related to oligomeric $\alpha$-syn in the SED 
group (Fig. 9b, $\mathrm{P}=0.0137, \mathrm{R}^{2}=0.099$ ). These findings suggest that the rate of physical activity can partially modulate total $\alpha$-syn accumulation, in particular with increasing age.

2) $\mathrm{A} \beta \mathrm{A}: \mathrm{A} \beta$ concentrations in RBCs were directly related to the physical activity level in the young subgroup (Fig. 9c, $\mathrm{P}=0.0207, \mathrm{R}^{2}=0.083$ ) and in ATHL ( $\mathrm{P}=0.0473, \mathrm{R}^{2}=0.097$, Fig. 9d). Any significant correlation was found in the whole population ( $\mathrm{P}=0.4605$, Suppl. Fig. 6a), in the elderly ( $\mathrm{P}=0.1010$, Suppl. Fig. 6b), or in SED ( $\mathrm{P}=0.9268$, Suppl. Fig. 6c). These data are consistent with the trend toward lower A $\beta$ levels observed in the young ATHL group than in the young SED group (see Fig. 4c).

3) Tau: RBC tau concentrations were found to be inversely related to physical activity level in the total cohort (Fig. 9e, $\mathrm{P}=0.0284, \mathrm{R}^{2}=0.046$ ). No other significant correlation was found in the other subgroups (Suppl. Fig. 6d-g, older: $\mathrm{P}=0.2397$; young: $\mathrm{P}=0.9908$; ATHL: $\mathrm{P}=0.9908$; SED: $\mathrm{P}=0.5029)$.

4) $\alpha$-syn/A $\beta$ : The grade of physical exercise was inversely correlated with $\alpha$-syn/A $\beta$ concentrations of $\mathrm{RBCs}$ in the total population (Fig. 9f, $\mathrm{P}=0.0001, \mathrm{R}^{2}=0.134$ ), as well as in young subjects (Fig. 9g, $\mathrm{P}=0.0006, \mathrm{R}^{2}=0.170$ ) and in elderly (Fig. 9h, $\mathrm{P}=0.047, \mathrm{R}^{2}=0.108$ ). These results suggest that the interaction of $\alpha$-syn with $A \beta$ is strongly modulated by the level of physical activity, independent of age. In contrast, no correlation was found in the ATHL (Suppl. Fig. 7a, P=0.3748) or SED populations (Suppl. Fig. 7b, $\mathrm{P}=0.8695$ ).

5) $\alpha$-syn/tau: No significant correlation between the physical activity level and $\alpha$-syn/tau was detected (whole population: $\mathrm{P}=0.6326$; older: $\mathrm{P}=0.8851$; young: $\mathrm{P}=0.3915$; ATHL: $\mathrm{P}=0.3915$; SED: $\mathrm{P}=0.3574$, Suppl. Fig. 7c-g), suggesting that the interaction of $\alpha$-syn with tau is poorly modulated by the level of physical activity.

\section{Covariate analysis}

In a covariate analysis, as expected, total $\alpha$-syn predicted the content of its oligomeric form $(\mathrm{Z}=2.969, \mathrm{P}=0.0030)$. Interestingly, $\alpha$-syn $/ \mathrm{A} \beta$ complexes were shown to be a significant predictor for $\mathrm{RBC}$ concentrations of both total $(\mathrm{Z}=3.392, \mathrm{P}=0.0007)$ and oligomeric $(\mathrm{Z}=3.136, \mathrm{P}=0.0017) \alpha$ syn.

AOC toward hydroxyl radicals was demonstrated to be a significant predictor for total $\alpha$-syn ( $Z=-$ 3.485, $\mathrm{P}=0.0005)$ and $\alpha$-syn $/ \mathrm{A} \beta$ complexes $(\mathrm{Z}=-3.786, \mathrm{P}=0.0002)$. Moreover, the physical activity level was shown to be a significant predictor for AOC toward hydroxyl radical $(\mathrm{P}=0.0166)$, tau $(\mathrm{P}=0.0282)$, and, especially, $\alpha$-syn $/ \mathrm{A} \beta$ complexes $(\mathrm{P}=0.0001)$.

\section{Influence of the Apo E genotypes}


Apo E, a plasma protein involved in lipoprotein metabolism [70], presents three major human isoforms, designated $\mathrm{APO} \varepsilon 2, \mathrm{APO} \varepsilon 3$, and $\mathrm{APO} \varepsilon 4$. Among these, the APO $\varepsilon 4$ allele, leading to enhanced levels of brain $A \beta$, has been strongly associated with age-related diseases, including AD [71]. Furthermore, oxidative stress [70] and physical activity [42, 72] have been shown to differently act on the $\varepsilon 4$ population. On this basis, the present total population was stratified into $\varepsilon 4-$ and non- $\varepsilon 4$ carriers (Table 1$)$.

As depicted in Figure 10 (panel a and b), in the non $\varepsilon 4$-carriers, total $\alpha$-syn ( $\mathrm{P}=0.8544)$, oligomeric $\alpha$-syn $(\mathrm{P}=0.2663), \mathrm{A} \beta(\mathrm{P}=0.4015)$, and $\alpha$-syn/tau $(\mathrm{P}=0.1443)$ levels did not significantly differ between the ATHL and SED population, which is consistent with the data obtained in the whole population. Conversely, tau (Fig. 10b, $\mathrm{P}=0.0333$ ) and $\alpha$-syn $/ \mathrm{A} \beta$ concentrations (Fig. 10b, $\mathrm{P}=0.0346$ ) were confirmed to be lower in the ATHL than in the SED population. Moreover, the interaction of $\alpha$-syn with $\mathrm{A} \beta$ was found to be inversely correlated with plasma AOC against hydroxyl radicals (Fig. 10c, $\mathrm{P}=0.0113, \mathrm{R}^{2}=0.195$ ) and with the level of physical exercise (Fig. 10d, $\mathrm{P}=0.0292$, $\mathrm{R}^{2}=0.067$ ). Similar to the results seen in the whole population (see Fig. 4), no significance differences between the SED and ATHL groups were found in RBC levels of total and oligomeric $\alpha$-syn, $A \beta$, or $\alpha$-syn/tau in $\varepsilon 4$ carriers (Fig. 11a and b). Interestingly, the concentration of $\alpha$-syn/A $\beta$ heterocomplexes ( $\mathrm{P}=0.0421$, Fig. 11b) were significantly lower in the $\varepsilon 4$-ATHL group than in the $\varepsilon 4-S E D$ group. Of note, $\alpha$-syn/A $\beta$ levels were inversely correlated with peroxyl TOSC values (Fig. 11c, $\left.\mathrm{P}=0.0090, \mathrm{R}^{2}=0.982\right)$.

Unfortunately, the number of subjects carrying the $\varepsilon 4$ allele was too low to further divide into young and older cohorts. 


\section{Discussion}

In the present study, the accumulation of misfolded proteins linked to NDs were related to the antioxidant capability (AOC) and physical activity in a cohort of 106 healthy subjects. The main conclusions of this work are as follows: i) the levels of tau and $A \beta$ were differently modulated with increasing age; ii) total $\alpha$-syn and $A \beta$ accumulation in elderly subjects showed an inverse correlation with AOC toward hydroxyl radicals and the level of physical activity; iii) for the first time, $\alpha$-syn was demonstrated to interact with $\mathrm{A} \beta$ and tau at a peripheral level; iv) $\alpha$-syn heterocomplexes were strongly related to hydroxyl AOC; and v) $\alpha$-syn/A $\beta$ concentrations were inversely correlated with the level of physical activity.

These results suggested that $\alpha$-syn heterocomplexes could be novel putative indicators to monitor antioxidant capacity and ND-related protein misfolding.

Oxidative stress has been suggested to be one of the potential common etiologies in various NDs because of its capability to trigger mitochondrial dysfunction, cellular damage, and an impairment of the DNA repair system, all of which have been known to be key factors in accelerating the aging process and ND development [1, 3, 28]. Particular attention has been paid to the relationship between oxidative stress and the accumulation of misfolded proteins, such as $\alpha$-syn, A $\beta$ and tau, which constitute the neuropathological hallmarks of $\mathrm{AD}, \mathrm{PD}$ and other neurodegenerative proteinopathies [6]. For example, oxidative stress has been shown to exacerbate $A \beta$ production and aggregation, as well as to promote tau phosphorylation, potentially inducing a vicious cycle of pathogenesis in $\mathrm{AD}[1,73]$. Similarly, mitochondrial dysfunction related to oxidative stress has been strongly associated with $\alpha$-syn accumulation and apoptosis of dopaminergic neurons in PD [74].

Misfolded proteins related to NDs are hypothesized to accumulate in the brain even decades before the appearance of symptoms [75-77]; furthermore, recent studies have demonstrated a cell-to-cell transmission of pathologic $\alpha$-syn and A $\beta$ in anatomically interconnected areas [78, 79]. Brain, CSF and blood concentrations of such protein aggregates seem to be in a dynamic equilibrium [80, 81], suggesting that increased production in the brain could be associated with increased concentrations in the blood as the result of oligomer transfer across the blood brain barrier [82-84]. Among blood cells, RBCs have been suggested to be particularly sensitive to oxidative stress and misfolded proteins $[45,46,85]$, exhibiting damage to cell membranes and decreased cell deformability, which is necessary for effective oxygen transport and delivery [85]. Based on these findings, recent efforts to study RBC concentrations of misfolded proteins and their relationship with oxidative stress or NDs have emerged $[45,46]$. In this context, preliminary data have shown a correlation between $\mathrm{A} \beta$ concentrations in the brain and RBCs $[42,45]$, suggesting that these blood cells are a good model to 
study alterations in the brain. Herein, RBCs, isolated from a cohort of 106 healthy volunteers, were used to measure the accumulation of $\alpha$-syn, $A \beta$, tau, and of their heterocomplexes, depending on the extent of the antioxidant capability or of physical exercise, which has become an important preventive and therapeutic tool in AD and PD [35, 86].

In our cohort, the antioxidant capability toward hydroxyl radicals decreased significantly with age in the total population and in the SED cohort, consistent with literature data reporting an inverse correlation between oxidative damage/antioxidant capacity and age [69, 87]. Surprisingly, AOC did not significantly differ between the young and elderly in the total cohort, and the young ATHL group showed significantly lower TOSC values toward hydroxyl than the older ATHL. We speculate that among the ATHL subgroup, additional factors, such as type and strength of exercise or the time since the last training, may interfere with such results. Consistent with this hypothesis, several factors, including diet, have been suggested to influence the extent of plasma AOC [44].

As expected, AOC toward hydroxyl and peroxyl radicals was significantly higher in the ATHL group than in the SED group, and the first directly correlated with the level of physical activity in the whole subpopulation and in older subjects. In this respect, regular exercise has been demonstrated to induce an adaptive response that involves the up-regulation of the enzymatic antioxidant system, culminating in a regulation of cellular redox state in brain cells [36, 37].

In contrast to plasma AOC, total and oligomeric $\alpha$-syn did not significantly change with age in the whole population. Consistent with these data, no correlation between RBC $\alpha$-syn oligomer levels and age has been found in PD patients [44]. Conversely, a recent paper has reported that plasma $\alpha$ syn levels correlated strongly with age, revealing much lower concentrations in older than younger individuals [85]. This discrepancy may be explained by considering the different peripheral fluids under examination or the sensitivity of the antibodies in the home-made immuno-enzymatic assays. Interestingly, total $\alpha$-syn significantly decreased with age in the ATHL population, whereas an opposite trend was found in the SED group, suggesting that physical activity could differently modulate $\alpha$-syn accumulation depending on age. Consistent with this hypothesis, total $\alpha$-syn levels in RBCs were significantly lower in the ATHL group than in the SED group in the elderly (but not in the young or total) population and were inversely correlated with physical exercise level and hydroxyl AOC. Overall, these findings suggest that plasma AOC and the rate of physical activity can partially modulate total $\alpha$-syn accumulation, in particular with increasing age. Consistent with our data, treadmill physical exercise has been shown to reduce $\alpha$-syn and oxidative stress in a rat model of PD [88].

$\mathrm{A} \beta$ levels in RBCs were found to progressively accumulate with age in the SED population, consistent with previous data from the literature obtained in the same blood cells [46]. Nevertheless, 
as shown for total $\alpha$-syn, the influence of oxidative stress and physical activity on $A \beta$ accumulation was relevant in the elderly subgroup only, in which $A \beta$ levels were inversely correlated with AOC toward hydroxyl radicals and were significantly lower in the ATHL group than in the SED group. Consistent with our findings, RBC A $\beta$ concentration positively correlates with an oxidative stress marker [46], and plasma $A \beta$ concentrations decreased with physical exercise in elderly subjects (mean age 70) [42]. Moreover, a relationship between physical activity and brain amyloid load, quantified by PET, has been reported in a few studies [72, 89].

RBC levels of total tau significantly decreased with age in the total and SED populations; in contrast, Sparks and co-workers have reported a slight but significant age-related increase in circulating tau among individuals maintaining a cognitive control status [90]. This discrepancy can be explained considering that the authors analyzed tau plasma levels. Further studies will be needed to clarify the significance of tau in RBCs decrease with age.

The tau concentration was lower in the ATHL population than in the SED population and was inversely related to physical activity level in the total cohort, thus suggesting that this parameter is modulated by physical exercise. Consistent with this hypothesis, long-term physical exercise has been shown to reduce both total and hyperphosphorylated tau in transgenic mice [91].

Then, $\alpha$-syn heteromeric association with $\mathrm{A} \beta$ or tau was analyzed in RBCs. $\alpha$-syn and tau have been shown to co-localize in neurons $[13,17,18]$ and within the axon compartment [19]; similarly, membrane-associated $\alpha$-syn has been demonstrated to interact with $\mathrm{A} \beta[14,15,92,93]$. However, the presence of $\alpha$-syn complexes with $\mathrm{A} \beta$ or tau in peripheral cells has not been investigated. Herein, by co-immunoprecipitation and immune-enzymatic assays, $\alpha$-syn was shown to form heterocomplexes with tau and $A \beta$. The interaction of $\alpha$-syn with tau or $A \beta$ in RBCs did not change with age; conversely, both $\alpha$-syn/A $\beta$ and $\alpha$-syn/tau concentrations were inversely correlated with hydroxyl AOC in the whole population and in older subjects. These data suggest that a higher plasma AOC toward hydroxyl radicals paralleled with lower concentrations of $\alpha$-syn heterocomplexes.

The levels of $\alpha$-syn/tau did not change with physical activity; conversely, significantly lower concentrations of $\alpha$-syn/A $\beta$ were found in the ATHL group versus the SED group in the whole cohort, as well as in the older and young subpopulation. In the three subgroups, the level of physical exercise inversely correlated with $\alpha$-syn/A $\beta$ concentrations of RBCs, suggesting that $\alpha$-syn/A $\beta$ levels in RBCs are modulated by physical activity, independent of age.

Finally, because only non $\varepsilon 4$-carriers have been shown to receive the benefits of antioxidants [69] or physical activity [42], the influence of the Apo E genotype on the content of protein aggregates was analyzed. Tau levels remained significantly higher in the ATHL group than in the SED group, 
suggesting that this parameter is not modulated by the Apo E isoform. As discussed above, the reduction in $\mathrm{A} \beta$ was only significant in older subjects; unfortunately, the low number of $\varepsilon 4$-carriers did not allow us to further divide the group into young and older subjects, which would have allowed for the evaluation of the influence of the Apo E genotype on A $\beta$ accumulation. Conversely, despite the low number of subjects, $\alpha$-syn/A $\beta$ concentrations were inversely correlated with AOC against peroxyl radicals in the $\varepsilon 4$-population and were lower in the $\varepsilon 4$-ATHL subjects than in the $\varepsilon 4-S E D$ subjects. These data suggest that the interaction of $\alpha$-syn with $A \beta$ is not related to Apo $E$ genotype, but rather, it can be influenced by the AOC toward peroxyl radicals in $\varepsilon 4$-carriers.

In conclusion, the negative role of oxidative stress and sedentary style in abnormal accumulation of ND-related proteins was shown in the present paper. Most importantly, for the first time, our data demonstrated the following: i) $\alpha$-syn heterocomplexes with $\mathrm{A} \beta$ and tau were expressed in RBCs; ii) the interaction of $\alpha$-syn with $A \beta$ and tau was influenced by plasma AOC towards hydroxyl radicals; and iii) $\alpha$-syn/A $\beta$ content inversely correlated with the physical activity level. Together, all of the data suggest that $\alpha$-syn heterocomplexes may represent potential new indicators to monitor antioxidant capacity and ND-related protein misfolding.

Future works will investigate the contribution of both oxidative stress and physical exercise on the accumulation of misfolded/hyperphosphorylated forms of ND-related proteins.

In interpreting such findings, it is important to note that our data were derived from a cohort of healthy subjects in peripheral fluids. Therefore, our results on $\alpha$-syn heterocomplexes should be considered as preliminary data. Further research will be needed to establish a correlation between peripheral and central content of $\alpha-\operatorname{syn} / \mathrm{A} \beta$ and $\alpha$-syn/tau, as well as to establish their role in pathological conditions of neurodegeneration. Finally, among the limitation of our study, the unfeasibility of measuring RBC turnover should be mentioned. Even if conflicting data on exercisemediated modulation of RBC production have been reported [94-98], the influence of exercise on RBC ageing/turnover will be take into consideration in a future study.

\section{Abbreviations:}

AOC antioxidant capacity

Apo E Apolipoprotein E

A $\boldsymbol{\beta} \beta$-amyloid $1-42$

$\alpha$-syn $\alpha$-synuclein

AD Alzheimer's disease

DLB Dementia with Lewy Bodies

NDs Neurodegenerative diseases 
PD Parkinson's disease

RBCs Red blood cells

ROS Reactive oxygen species.

TOSC Total Oxyradical Scavenging Capacity.

\section{Acknowledgments}

This work was supported by PRA2016 (539999_2015 to F.F) and "Clinical research and innovation -scouting project" to C.M. We thank Dr. Chiara Giacomelli for her manuscript revising. A special acknowledgement is due to healthy individuals for their participation in this study.

\section{Authors' contributions}

SD, MLT, GS, UB and GS were involved with the conception, design, and interpretation of data. SD, DP, JF, CI, LP, ALG and LC performed the experiments. SD, DP, JF, FG, MLT, FF and FB were involved with data analysis. LP and FB collected the clinical material. CM, GS, MLT, GS and UB provided general overall supervision of the study, and acquired funding. All authors contributed to the drafting and critical revision of the manuscript and have given final approval of the version to be published. 


\section{Figure Legends}

Fig. 1 Presence of $\alpha$-syn, $A \beta$, tau and their heterocomplexes in blood cells. a Cell lysates obtained from RBCs were subjected to Western blot analysis using antibody to $\alpha$-syn, A $\beta$ or tau. GAPDH was the loading control. b Cell lysates obtained from RBCs were immunoprecipitated with an anti$\alpha$-syn antibody, and then immunoblotted with antibody to $\alpha$-syn, A $\beta$ or tau. One representative Western blot is presented for each condition.

Fig. 2 In vitro determination of $\alpha$-syn/A $\beta$ heterocomplexes. a Human recombinant $\alpha$-syn/A $\beta$ (first line) was immunoprecipitated with an anti- $\alpha$-syn antibody, and then immunoblotted with antibody to $\alpha$-syn or $A \beta$. Recombinant $A \beta$ alone (second line) was used as a positive control. One representative Western blot is presented for each condition. b, c Different concentrations of human recombinant $\alpha$-syn/A $\beta$ were captured on wells pre-coated with an anti-A $\beta$ antibody. After extensive washes, levels of the $\alpha$-syn/A $\beta$ complex were quantified using an antibody specific for $\alpha$-syn, and subsequently an HRP-conjugated antibody and a TMB substrate kit. Blank wells were obtained in the absence of $\alpha$-syn antibody. c The theoretical $\alpha$-syn/A $\beta$ concentrations were subtracted of the quote of free syn, not bound to $A \beta$. Data are expressed as absorbance at $450 \mathrm{~nm}$ minus blank values, and are the mean \pm SEM of at least three independent experiments.

Fig. 3 In vitro determination of $\alpha$-syn/tau heterocomplexes. a Human recombinant $\alpha$-syn/tau (first line) was immunoprecipitated with an anti- $\alpha$-syn antibody, and then immunoblotted with antibody to $\alpha$-syn or tau. Recombinant tau alone (second line) was used as a positive control. One representative Western blot is presented for each condition. b, c Different concentrations of human recombinant $\alpha$-syn/tau were captured on wells pre-coated with an anti-tau antibody. After extensive washes, levels of the $\alpha$-syn/tau complex were quantified using an antibody specific for $\alpha$-syn, and subsequently an HRP-conjugated antibody and a TMB substrate kit. Blank wells were obtained in the absence of $\alpha$-syn antibody. $\mathbf{c}$ The theoretical $\alpha$-syn/tau concentrations were subtracted of the quote of free syn, not bound to tau. Data are expressed as absorbance at $450 \mathrm{~nm}$ minus blank values, and are the mean \pm SEM of at least three independent experiments.

Fig. 4 Determination of ND-related proteins in RBCs. a-f RBC levels of total $\alpha$-syn (a), oligomeric $\alpha$-syn (b), A $\beta$ (c), tau (d), $\alpha$-syn/A $\beta$ (e) and $\alpha$-syn/tau (f) in the total cohort, in young and older subgroups of ATHL and SED subjects (mean \pm SD). Lysates obtained from RBCs were subjected to specific immunoassay, as described in the Methods section. $* \mathrm{P}<0.05$, $* * * \mathrm{P}<0.001$ versus other subgroups. 
Fig. 5 Determination of plasma AOC in human subjects. a, b Plasma total oxyradical scavenging capacity (TOSC) against hydroxyl (a) and peroxyl (b) radicals in the total cohort, in young and older subgroups of ATHL and SED subjects (mean $\pm \mathrm{SD}$ ). $* \mathrm{P}<0.05$, $* * \mathrm{P}<0.01, * * * \mathrm{P}<0.001$ versus other subgroups. c-f Correlation analysis between TOSC values against hydroxyl or peroxyl radicals and level of physical activity, expressed as Physical Activity level.

Fig. 6 Correlation between ND-related proteins and plasma AOC. a-c Correlation analysis between total $\alpha$-syn concentrations in RBCs (a-c) and TOSC values against hydroxyl radicals in the total cohort (a), older cohort (b), young cohort (c) or in ATHL (d). e Correlation analysis between A $\beta$ concentrations in RBCs and TOSC values against hydroxyl radicals in the older cohort. $\mathbf{f}$ Correlation analysis between tau concentrations in RBCs and TOSC values against hydroxyl radicals in ATHL.

Fig. 7 Correlation between $\alpha$-syn/A $\beta$ content in RBCs and plasma AOC. a-d Correlation analysis between $\alpha$-syn/A $\beta$ concentrations in RBCs and TOSC values against hydroxyl radicals in the total cohort (a), older cohort (b), young cohort (c), in ATHL (d) or in SED (e).

Fig. 8 Correlation between $\alpha$-syn/tau content in RBCs and plasma AOC. a-c Correlation analysis between $\alpha$-syn/tau concentrations in RBCs and TOSC values against hydroxyl radicals in the total cohort (a), older cohort (b), in ATHL (c), in SED (d) or in the young cohort (e).

Fig. 9 Correlation between ND-related proteins and physical exercise. a-d Correlation analysis between level of physical activity and RBC concentrations of total $\alpha$-syn (a), oligomeric $\alpha$-syn (b), $\mathrm{A} \beta(\mathbf{c})$, tau $(\mathbf{d})$ and $\alpha$-syn/A $\beta(\mathbf{e}, \mathbf{f}, \mathbf{g})$ in the indicated subgroups.

Fig. 10 ND-related proteins in non $\varepsilon 4$-carriers. a, b RBC levels of total $\alpha$-syn, oligomeric $\alpha$-syn, A $\beta, \alpha$-syn/A $\beta$, tau and $\alpha$-syn/tau in subjects not carrying the $\varepsilon 4$ allele (total cohort, ATHL and SED subjects). Lysates obtained from RBCs were subjected to specific immunoassay, as described in the Methods section. The data are the mean $\pm \mathrm{SD}$. ${ }^{*} \mathrm{P}<0.05$ ATHL versus SED. c, d Correlation analysis between RBC concentrations of $\alpha$-syn/A $\beta$ and TOSC values against hydroxyl radicals (c) or level of physical activity (d) in subjects not carrying the $\varepsilon 4$ allele.

Fig. 11 ND-related proteins in $\varepsilon 4$-carriers. a, b RBC levels of total $\alpha$-syn, oligomeric $\alpha$-syn, A $\beta, \alpha$ syn/A $\beta$, tau and $\alpha$-syn/tau in subjects carrying the e4 allele (total cohort, ATHL and SED subjects). Lysates obtained from RBCs were subjected to specific immunoassay, as described in the Methods section. The data are the mean $\pm \mathrm{SD}$. $* * \mathrm{P}<0.01$ ATHL versus SED. c Correlation analysis between 
$\mathrm{RBC}$ concentrations of $\alpha$-syn/A $\beta$ and TOSC values against peroxyl radicals in subjects carrying the $\varepsilon 4$ allele. 


\section{References}

1. Kim GH, Kim JE, Rhie SJ, Yoon S (2015) The Role of Oxidative Stress in Neurodegenerative Diseases. Exp Neurobiol 24:325-340

2. Lin MT, Beal MF (2006) Mitochondrial dysfunction and oxidative stress in neurodegenerative diseases. Nature 443:787-795

3. Gandhi S, Abramov AY (2012) Mechanism of oxidative stress in neurodegeneration. Oxid Med Cell Longev. doi:10.1155/2012/428010

4. Dalle-Donne I, Aldini G, Carini M, Colombo R, Rossi R, Milzani A (2006) Protein carbonylation, cellular dysfunction, and disease progression. J Cell Mol Med 10:389-406

5. Klein WL, Stine WB, Teplow DB (2004) Small assemblies of unmodified amyloid betaprotein are the proximate neurotoxin in Alzheimer's disease. Neurobiol Aging 25:569-580

6. Ugalde CL, Finkelstein DI, Lawson VA, Hill AF (2016) Pathogenic mechanisms of prion protein, amyloid- $\beta$ and $\alpha$-synuclein misfolding: the prion concept and neurotoxicity of protein oligomers. J Neurochem 139:162-180

7. Goedert M, Spillantini MG, Del Tredici K, Braak H (2013) 100 years of Lewy pathology. Nat Rev Neurol 9:13-24

8. Maurer K, Volk S, Gerbaldo H (1997) Auguste D and Alzheimer's disease. Lancet 349:1546-1549

9. Serrano-Pozo A, Frosch MP, Masliah E, Hyman BT (2011) Neuropathological alterations in Alzheimer disease. Cold Spring Harb Perspect Med. doi:10.1101/cshperspect.a006189

10. Larson ME, Sherman MA, Greimel S, Kuskowski M, Schneider JA, Bennett DA, Lesné SE (2012) Soluble $\alpha$-synuclein is a novel modulator of Alzheimer's disease pathophysiology. J Neurosci 32:10253-10266

11. Marsh SE, Blurton-Jones M (2012) Examining the mechanisms that link $\beta$-amyloid and $\alpha$ synuclein pathologies. Alzheimers Res Ther 4:11

12. Trojanowski JQ (2002) "Emerging Alzheimer's disease therapies: focusing on the future". Neurobiol Aging 23:985-990

13. Lee VM, Giasson BI, Trojanowski JQ (2004) More than just two peas in a pod: common amyloidogenic properties of tau and alpha-synuclein in neurodegenerative diseases. Trends Neurosci 27:129-134

14. Mandal PK, Pettegrew JW, Masliah E, Hamilton RL, Mandal R (2006) Interaction between Abeta peptide and alpha synuclein: molecular mechanisms in overlapping pathology of Alzheimer's and Parkinson's in dementia with Lewy body disease. Neurochem Res 31:1153-1162

15. Tsigelny IF, Crews L, Desplats P, Shaked GM, Sharikov Y, Mizuno H, Spencer B, Rockenstein E, Trejo M, Platoshyn O, Yuan JX, Masliah E (2008) Mechanisms of hybrid oligomer formation in the pathogenesis of combined Alzheimer's and Parkinson's diseases. PLoS One. doi:10.1371/journal.pone.0003135

16. Benussi L, Ghidoni R, Paterlini A, Nicosia F, Alberici AC, Signorini S, Barbiero L, Binetti $\mathrm{G}$ (2005) Interaction between tau and alpha-synuclein proteins is impaired in the presence of P301L tau mutation. Exp Cell Res 308:78-84

17. Badiola N, de Oliveira RM, Herrera F, Guardia-Laguarta C, Gonçalves SA, Pera M, SuárezCalvet M, Clarimon J, Outeiro TF, Lleó A (2011) Tau enhances $\alpha$-synuclein aggregation and toxicity in cellular models of synucleinopathy. PLoS One. doi:10.1371/journal.pone.0026609

18. Giasson BI, Forman MS, Higuchi M, Golbe LI, Graves CL, Kotzbauer PT, Trojanowski JQ, Lee VM (2003) Initiation and synergistic fibrillization of tau and alpha-synuclein. Science 300:636640

19. Jensen PH, Hager H, Nielsen MS, Hojrup P, Gliemann J, Jakes R (1999) alpha-synuclein binds to Tau and stimulates the protein kinase A-catalyzed tau phosphorylation of serine residues 262 and 356. J Biol Chem 274:25481-25489

20. Growdon JH (1999) Biomarkers of Alzheimer disease. Arch Neurol 56:281-283 
21. Garlind A, Brauner A, Höjeberg B, Basun H, Schultzberg M (1999) Soluble interleukin-1 receptor type II levels are elevated in cerebrospinal fluid in Alzheimer's disease patients. Brain Res 826:112-116

22. Hock C, Heese K, Müller-Spahn F, Huber P, Riesen W, Nitsch RM, Otten U (2000) Increased CSF levels of nerve growth factor in patients with Alzheimer's disease. Neurology 54:2009-2011

23. Hampel H, Buerger K, Kohnken R, Teipel SJ, Zinkowski R, Moeller HJ, Rapoport SI, Davies P (2001) Tracking of Alzheimer's disease progression with cerebrospinal fluid tau protein phosphorylated at threonine 231. Ann Neurol 49:545-546

24. Andreasen N, Minthon L, Davidsson P, Vanmechelen E, Vanderstichele H, Winblad B, Blennow K (2001) Evaluation of CSF-tau and CSF-Abeta42 as diagnostic markers for Alzheimer disease in clinical practice. Arch Neurol 58:373-379

25. Reiber H (2003) Proteins in cerebrospinal fluid and blood: barriers, CSF flow rate and source-related dynamics. Restor Neurol Neurosci 21:79-96

26. Chen X, Guo C, Kong J (2012) Oxidative stress in neurodegenerative diseases. Neural Regen Res 7:376-85.

27. Williams A (2002) Defining neurodegenerative diseases. BMJ 324:1465-1466

28. Patten DA, Germain M, Kelly MA, Slack RS (2010) Reactive oxygen species: stuck in the middle of neurodegeneration. J Alzheimers Dis 20 Suppl 2:S357-367

29. Ienco EC, LoGerfo A, Carlesi C, Orsucci D, Ricci G, Mancuso M, Siciliano G (2011) Oxidative stress treatment for clinical trials in neurodegenerative diseases. J Alzheimers Dis 24 Suppl 2:111-126

30. Navarro A, Boveris A (2010) Brain mitochondrial dysfunction in aging, neurodegeneration, and Parkinson's disease. Front Aging Neurosci. doi:10.3389/fnagi.2010.00034

31. Fulda S, Gorman AM, Hori O, Samali A (2010) Cellular stress responses: cell survival and cell death. Int J Cell Biol. doi:10.1155/2010/214074

32. Halliwell B (1994) Free radicals, antioxidants, and human disease: curiosity, cause, or consequence? Lancet 344:721-4

33. Feng Y, Wang X (2012) Antioxidant therapies for Alzheimer's disease. Oxid Med Cell Longev. doi:10.1155/2012/472932

34. Singh S (2015) Antioxidants as a preventive therapeutic option for age related neurodegenerative diseases. Ther Targets Neurol Dis. doi:http://dx.doi.org/10.14800/ttnd.592

35. Mattson MP, Magnus T (2006) Ageing and neuronal vulnerability. Nat Rev Neurosci 7:278294

36. Radak Z, Suzuki K, Higuchi M, Balogh L, Boldogh I, Koltai E (2016) Physical exercise, reactive oxygen species and neuroprotection. Free Radic Biol Med 98:187-196

37. Voss MW, Vivar C, Kramer AF, van Praag H (2013) Bridging animal and human models of exercise-induced brain plasticity. Trends Cogn Sci 17:525-544

38. Power GA, Dalton BH, Rice CL (2013) Human neuromuscular structure and function in old age: A brief review. J Sport Health Sci 2:215-226

39. Johnson RA, Mitchell GS (2003) Exercise-induced changes in hippocampal brain-derived neurotrophic factor and neurotrophin-3: effects of rat strain. Brain Res 983:108-114

40. Lazarov O, Robinson J, Tang YP, Hairston IS, Korade-Mirnics Z, Lee VM, et al (2005) Environmental enrichment reduces Abeta levels and amyloid deposition in transgenic mice. Cell 120:701-713

41. Tapia-Rojas C, Aranguiz F, Varela-Nallar L, Inestrosa NC (2016) Voluntary Running Attenuates Memory Loss, Decreases Neuropathological Changes and Induces Neurogenesis in a Mouse Model of Alzheimer's Disease. Brain Pathol 26:62-74

42. Brown BM, Peiffer JJ, Taddei K, Lui JK, Laws SM, Gupta VB, et al (2013) Physical activity and amyloid- $\beta$ plasma and brain levels: results from the Australian Imaging, Biomarkers and Lifestyle Study of Ageing. Mol Psychiatry 18:875-881 
43. Ang ET, Tai YK, Lo SQ, Seet R, Soong TW (2010) Neurodegenerative diseases: exercising toward neurogenesis and neuroregeneration. Front Aging Neurosci. doi:10.3389/fnagi.2010.00025

44. Pandey KB, Rizvi SI (2010) Markers of oxidative stress in erythrocytes and plasma during aging in humans. Oxid Med Cell Longev 3:2-12

45. Wang X, Yu S, Li F, Feng T (2015) Detection of $\alpha$-synuclein oligomers in red blood cells as a potential biomarker of Parkinson's disease. Neurosci Lett 599:115-119

46. Kiko T, Nakagawa K, Satoh A, Tsuduki T, Furukawa K, Arai H, et al (2012) Amyloid $\beta$ levels in human red blood cells. PLoS One. doi:10.1371/journal.pone.0049620

47. Whaley MH, Brubaker PH, Otto RM, Armstrong LE (2006) Medicine ACoS Guidelines for exercise testing and prescription. 7th ed. Lippincott Williams \& Wilkins, Philadelphia

48. Borg GA (1982) Psychophysical bases of perceived exertion. Med Sci Sports Exerc 14:377381

49. Hamer P, Slocombe B (1997) The psychophysical and heart rate relationship between treadmill and deep-water running. Aust J Physiother 43:265-271

50. Costa B, Bendinelli S, Gabelloni P, Da Pozzo E, Daniele S, Scatena F, et al (2013) Human glioblastoma multiforme: p53 reactivation by a novel MDM2 inhibitor. PLoS One. doi:10.1371/journal.pone.0072281

51. Foulds PG, Mitchell JD, Parker A, Turner R, Green G, Diggle P, et al (2011) Phosphorylated $\alpha$-synuclein can be detected in blood plasma and is potentially a useful biomarker for Parkinson's disease. FASEB J 25:4127-4137

52. El-Agnaf OM, Salem SA, Paleologou KE, Curran MD, Gibson MJ, Court JA, et al (2006) Detection of oligomeric forms of alpha-synuclein protein in human plasma as a potential biomarker for Parkinson's disease. FASEB J 20:419-425

53. Pesini P, Pérez-Grijalba V, Monleón I, Boada M, Tárraga L, Martínez-Lage P, et al (2012) Reliable Measurements of the $\beta$-Amyloid Pool in Blood Could Help in the Early Diagnosis of AD. Int J Alzheimers Dis. doi:10.1155/2012/604141

54. Zappelli E, Daniele S, Abbracchio MP, Martini C, Trincavelli ML (2014) A rapid and efficient immunoenzymatic assay to detect receptor protein interactions: $G$ protein-coupled receptors. Int J Mol Sci 15:6252-6264

55. Daniele S, Taliani S, Da Pozzo E, Giacomelli C, Costa B, Trincavelli ML, et al (2014) Apoptosis therapy in cancer: the first single-molecule co-activating p53 and the translocator protein in glioblastoma. Sci Rep 4:4749

56. Winston GW, Regoli F, Dugas AJ, Fong JH, Blanchard KA (1998) A rapid gas chromatographic assay for determining oxyradical scavenging capacity of antioxidants and biological fluids. Free Radic Biol Med 24:480-493

57. Regoli F, Winston GW (1999) Quantification of total oxidant scavenging capacity of antioxidants for peroxynitrite, peroxyl radicals, and hydroxyl radicals. Toxicol Appl Pharmacol 156:96-105

58. Franzoni F, Ghiadoni L, Galetta F, Plantinga Y, Lubrano V, Huang Y, et al (2005) Physical activity, plasma antioxidant capacity, and endothelium-dependent vasodilation in young and older men. Am J Hypertens 18:510-516

59. Bianchi S, Fusi J, Franzoni F, Giovannini L, Galetta F, Mannari C, et al (2016) Effects of recombinant human erythropoietin high mimicking abuse doses on oxidative stress processes in rats. Biomed Pharmacother 82:355-363

60. Franzoni F, Colognato R, Galetta F, Laurenza I, Barsotti M, Di Stefano R, et al (2006) An in vitro study on the free radical scavenging capacity of ergothioneine: comparison with reduced glutathione, uric acid and trolox. Biomed Pharmacother 60:453-457

61. Bartels T, Choi J, Kim N, Selkoe D (2011) Non-denaturing purification of alpha-Synuclein from erythrocytes. Protoc Exch. doi:10.1038/protex.2011.254 
62. Nielsen H, Ek D, Avdic U, Orbjörn C, Hansson O, Veerhuis R, et al (2013) NG2 cells, a new trail for Alzheimer's disease mechanisms? Acta Neuropathol Commun. doi:10.1186/20515960-1-7

63. Cerf E, Sarroukh R, Tamamizu-Kato S, Breydo L, Derclaye S, Dufrêne YF, et al (2009) Antiparallel beta-sheet: a signature structure of the oligomeric amyloid beta-peptide. Biochem $\mathrm{J}$ 421:415-423

64. Kostylev MA, Kaufman AC, Nygaard HB, Patel P, Haas LT, Gunther EC, et al (2015) Prion-Protein-interacting Amyloid- $\beta$ Oligomers of High Molecular Weight Are Tightly Correlated with Memory Impairment in Multiple Alzheimer Mouse Models. J Biol Chem 290:17415-38

65. Jimenez S, Navarro V, Moyano J, Sanchez-Mico M, Torres M, Davila JC, et al. Disruption of amyloid plaques integrity affects the soluble oligomers content from Alzheimer disease brains. PLoS One. 2014;9(12):e114041.

66. Barbour R, Kling K, Anderson JP, Banducci K, Cole T, Diep L, et al (2008) Red blood cells are the major source of alpha-synuclein in blood. Neurodegener Dis 5:55-59

67. Buée L, Bussière T, Buée-Scherrer V, Delacourte A, Hof PR (2000) Tau protein isoforms, phosphorylation and role in neurodegenerative disorders. Brain Res Brain Res Rev 33:95-130

68. Santpere G, Puig B, Ferrer I (2006) Low molecular weight species of tau in Alzheimer's disease are dependent on tau phosphorylation sites but not on delayed post-mortem delay in tissue processing. Neurosci Lett 399:106-10

69. Goraca A (2004) Assessment of total antioxidant capacity in human plasma. Folia Med (Plovdiv) 46:16-21

70. Dose J, Huebbe P, Nebel A, Rimbach G (2016) APOE genotype and stress response - a mini review. Lipids Health Dis 15:121

71. Rowe CC, Ellis KA, Rimajova M, Bourgeat P, Pike KE, Jones G, et al (2010) Amyloid imaging results from the Australian Imaging, Biomarkers and Lifestyle (AIBL) study of aging. Neurobiol Aging 31:1275-1283

72. Head D, Bugg JM, Goate AM, Fagan AM, Mintun MA, Benzinger T, et al (2012) Exercise Engagement as a Moderator of the Effects of APOE Genotype on Amyloid Deposition. Arch Neurol 69:636-643

73. Zhao Y, Zhao B (2013) Oxidative stress and the pathogenesis of Alzheimer's disease. Oxid Med Cell Longev. doi:10.1155/2013/316523

74. Blesa J, Trigo-Damas I, Quiroga-Varela A, Jackson-Lewis VR (2015) Oxidative stress and Parkinson's disease. Front Neuroanat 9:91

75. Danev SI, St Stoyanov D (2010) Early noninvasive diagnosis of neurodegenerative diseases. Folia Med (Plovdiv) 52:5-13

76. Price JL, McKeel DW, Buckles VD, Roe CM, Xiong C, Grundman M, et al (2009) Neuropathology of nondemented aging: presumptive evidence for preclinical Alzheimer disease. Neurobiol Aging 30:1026-1036

77. Paoluzzi L, Singh AS, Price DK, Danesi R, Mathijssen RH, Verweij J, et al (2004) Influence of genetic variants in UGT1A1 and UGT1A9 on the in vivo glucuronidation of SN-38. J Clin Pharmacol 44:854-860

78. Luk KC, Kehm V, Carroll J, Zhang B, O'Brien P, Trojanowski JQ, et al (2012) Pathological $\alpha$-synuclein transmission initiates Parkinson-like neurodegeneration in nontransgenic mice. Science 338:949-953

79. Ridley RM, Baker HF, Windle CP, Cummings RM (2006) Very long term studies of the seeding of beta-amyloidosis in primates. J Neural Transm (Vienna) 113:1243-1251

80. Kawarabayashi T, Younkin LH, Saido TC, Shoji M, Ashe KH, Younkin SG (2001) Agedependent changes in brain, CSF, and plasma amyloid (beta) protein in the Tg2576 transgenic mouse model of Alzheimer's disease. J Neurosci 21:372-381 
81. Ghersi-Egea JF, Gorevic PD, Ghiso J, Frangione B, Patlak CS, Fenstermacher JD (1996) Fate of cerebrospinal fluid-borne amyloid beta-peptide: rapid clearance into blood and appreciable accumulation by cerebral arteries. J Neurochem 67:880-883

82. Zlokovic BV (2004) Clearing amyloid through the blood-brain barrier. J Neurochem 89:807-11

83. Eisele YS, Obermüller U, Heilbronner G, Baumann F, Kaeser SA, Wolburg H, et al (2010) Peripherally applied Abeta-containing inoculates induce cerebral beta-amyloidosis. Science 330:980-982

84. DeMattos RB, Bales KR, Cummins DJ, Dodart JC, Paul SM, Holtzman DM (2001) Peripheral anti-A beta antibody alters CNS and plasma A beta clearance and decreases brain A beta burden in a mouse model of Alzheimer's disease. Proc Natl Acad Sci U S A 98:8850-8855

85. Mohanty JG, Nagababu E, Rifkind JM (2014) Red blood cell oxidative stress impairs oxygen delivery and induces red blood cell aging. Front Physiol 5:84

86. Radak Z, Hart N, Sarga L, Koltai E, Atalay M, Ohno H, et al (2010) Exercise plays a preventive role against Alzheimer's disease. J Alzheimers Dis 20:777-783

87. Inal ME, Kanbak G, Sunal E (2001) Antioxidant enzyme activities and malondialdehyde levels related to aging. Clin Chim Acta 305:75-80

88. Tuon T, Valvassori SS, Lopes-Borges J, Luciano T, Trom CB, Silva LA, et al (2012) Physical training exerts neuroprotective effects in the regulation of neurochemical factors in an animal model of Parkinson's disease. Neuroscience 227:305-312

89. Liang KY, Mintun MA, Fagan AM, Goate AM, Bugg JM, Holtzman DM, et al (2010) Exercise and Alzheimer's disease biomarkers in cognitively normal older adults. Ann Neurol 68:311-318

90. Sparks DL, Kryscio RJ, Sabbagh MN, Ziolkowski C, Lin Y, Sparks LM, et al (2012) Tau is reduced in AD plasma and validation of employed ELISA methods. Am J Neurodegener Dis 1:99106

91. Ohia-Nwoko O, Montazari S, Lau YS, Eriksen JL (2014) Long-term treadmill exercise attenuates tau pathology in P301S tau transgenic mice. Mol Neurodegener 9:54

92. Jensen PH, Nielsen MS, Jakes R, Dotti CG, Goedert M (1998) Binding of alpha-synuclein to brain vesicles is abolished by familial Parkinson's disease mutation. J Biol Chem 273:2629226294

93. Masliah E, Rockenstein E, Veinbergs I, Sagara Y, Mallory M, Hashimoto M, et al (2001) beta-amyloid peptides enhance alpha-synuclein accumulation and neuronal deficits in a transgenic mouse model linking Alzheimer's disease and Parkinson's disease. Proc Natl Acad Sci U S A 98:12245-12250

94. Smith JA (1995) Exercise, training and red blood cell turnover. Sports Med 19:9-31

95. Kaestner L, Bogdanova A (2014) Regulation of red cell life-span, erythropoiesis, senescence, and clearance. Front Physiol 5:269

96. Lombardi G, Colombini A, Lanteri P, Banfi G (2013) Reticulocytes in sports medicine: an update. Adv Clin Chem 59:125-53

97. Hu M, Lin W (2012) Effects of exercise training on red blood cell production: implications for anemia. Acta Haematol 127:156-64

98. Díaz V, Lombardi G, Ricci C, Jacobs RA, Montalvo Z, Lundby C, et al (2011) Reticulocyte and haemoglobin profiles in elite triathletes over four consecutive seasons. Int $\mathrm{J}$ Lab Hematol $33: 638-44$ 
Figure 1

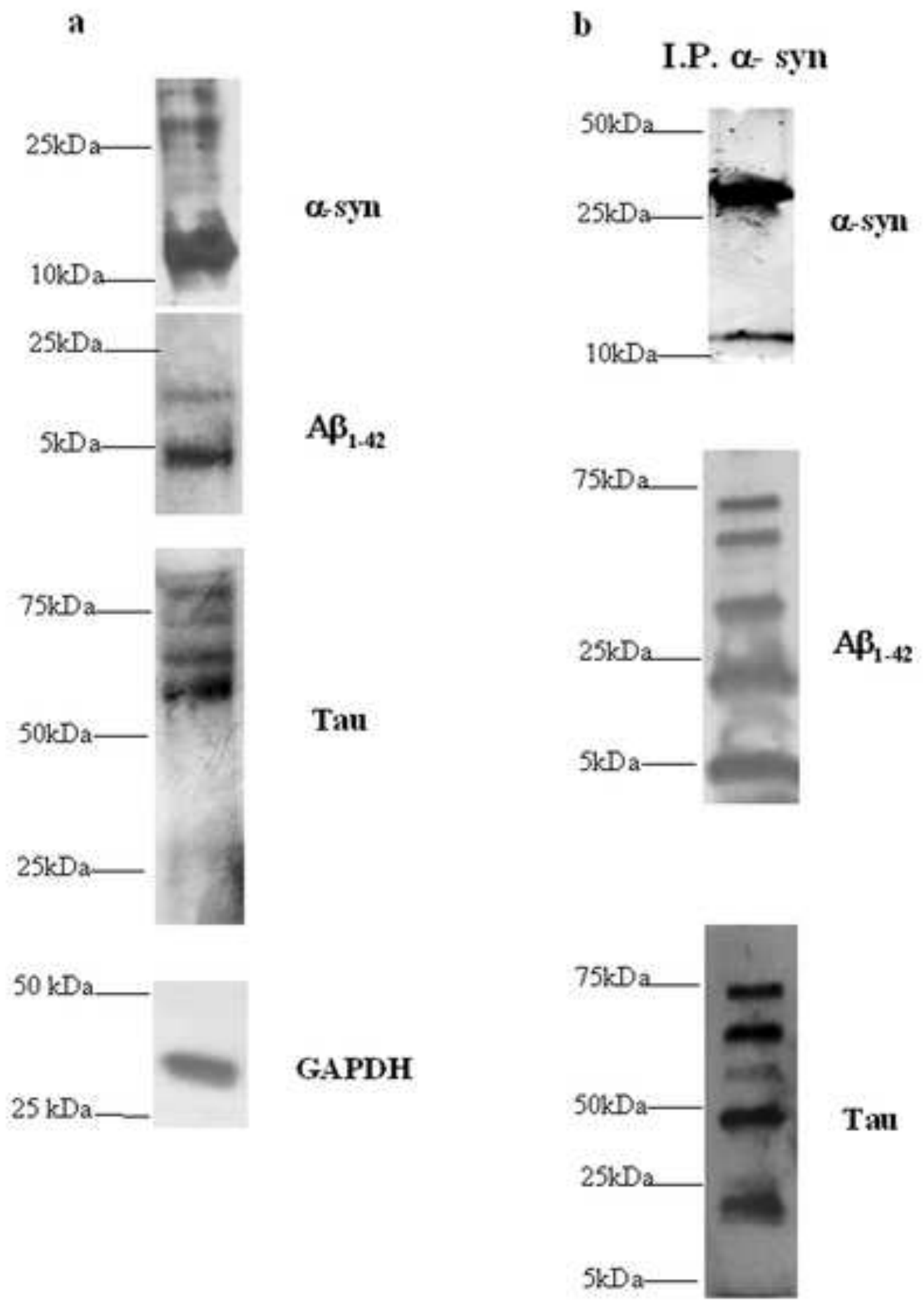




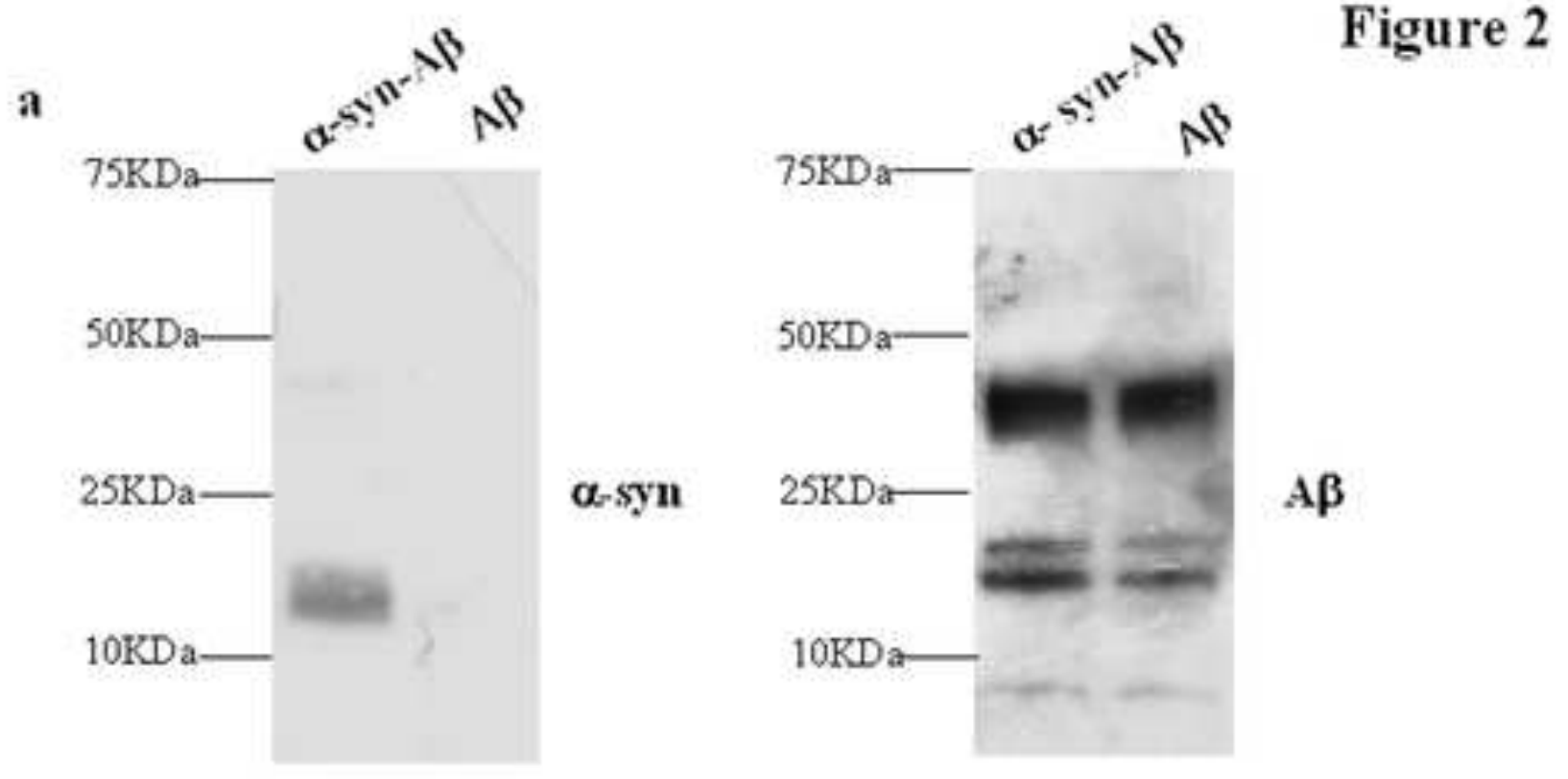

b

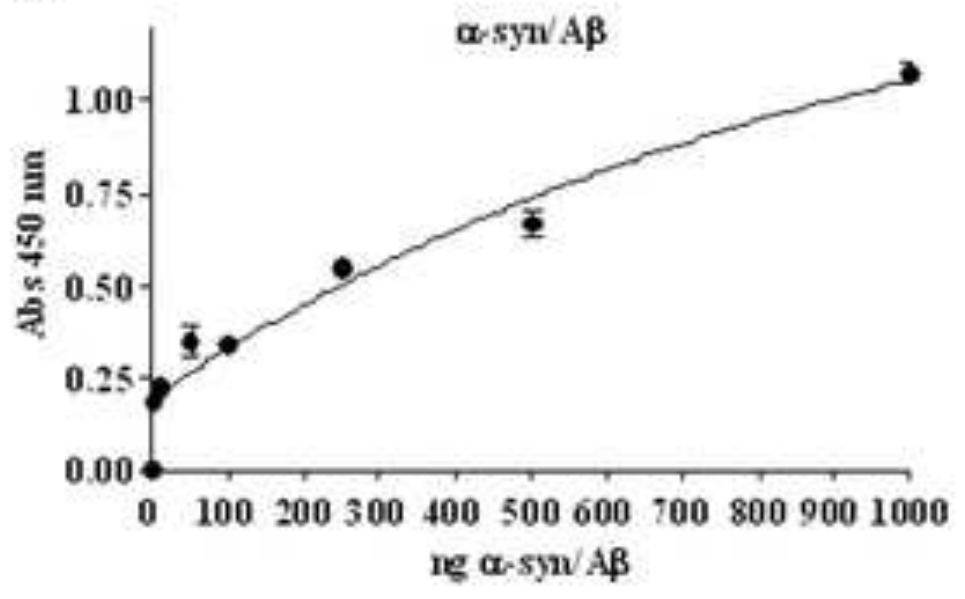

c

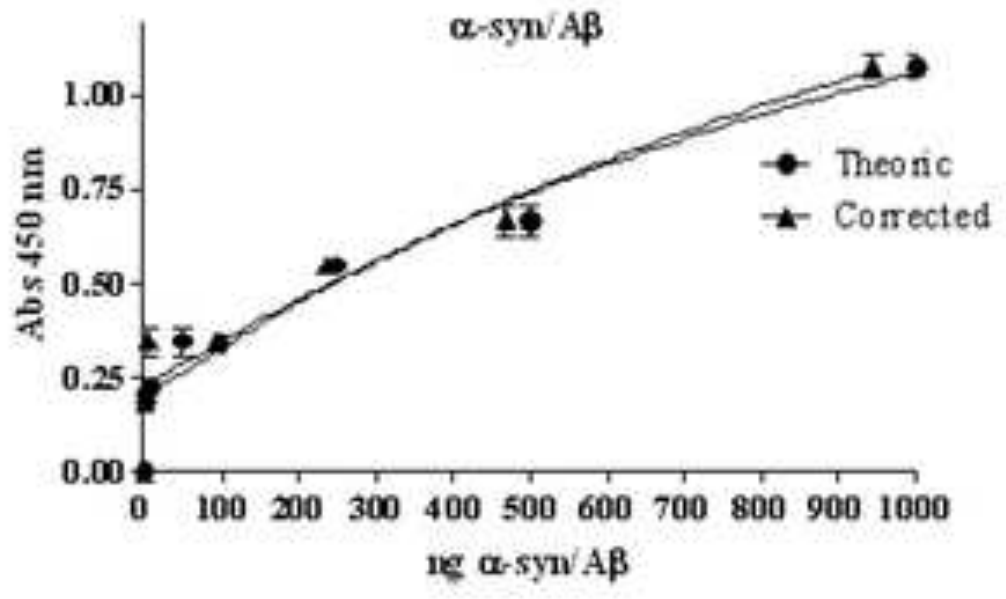



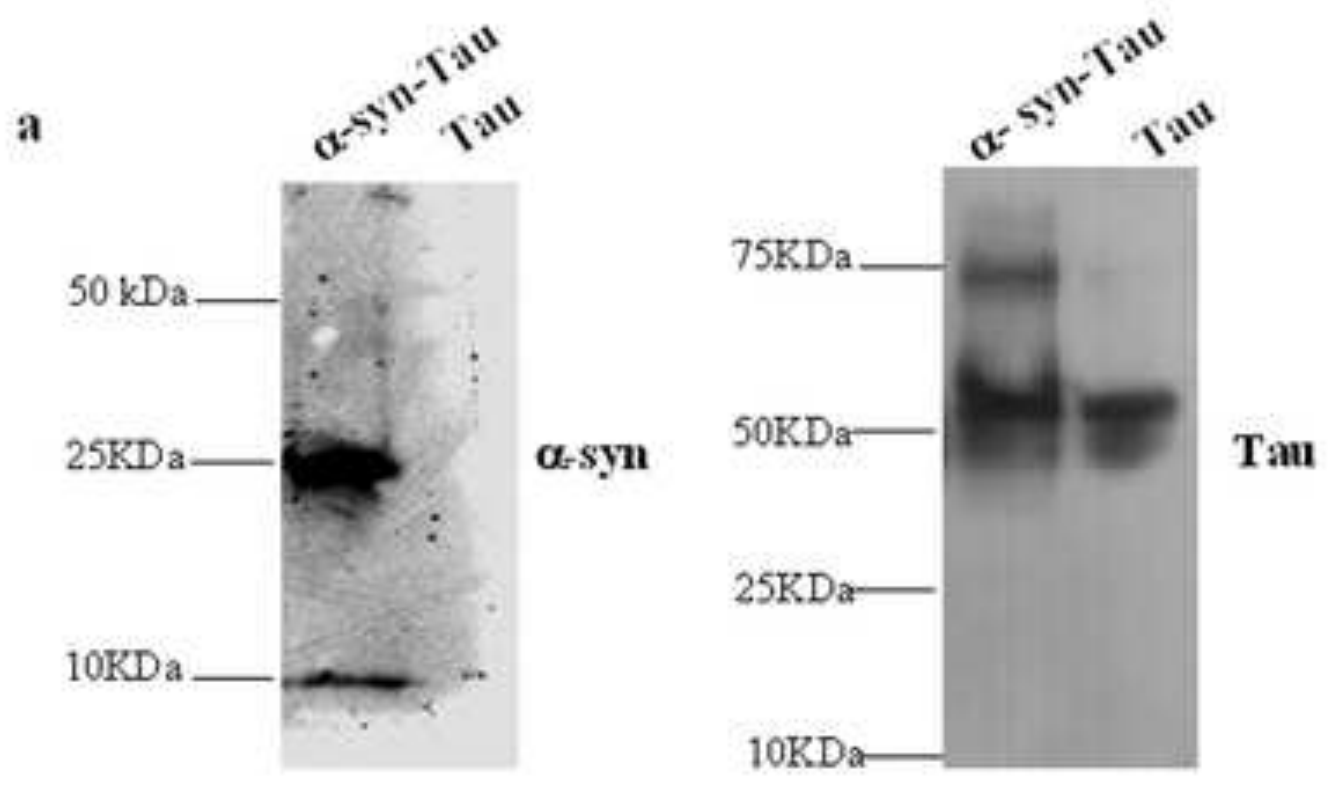

Figure 3

b

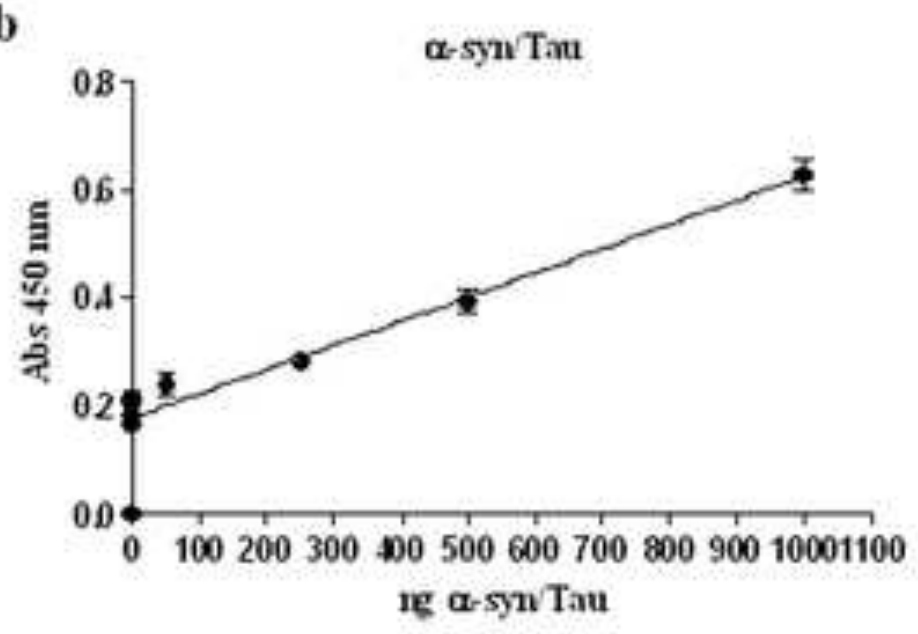

c

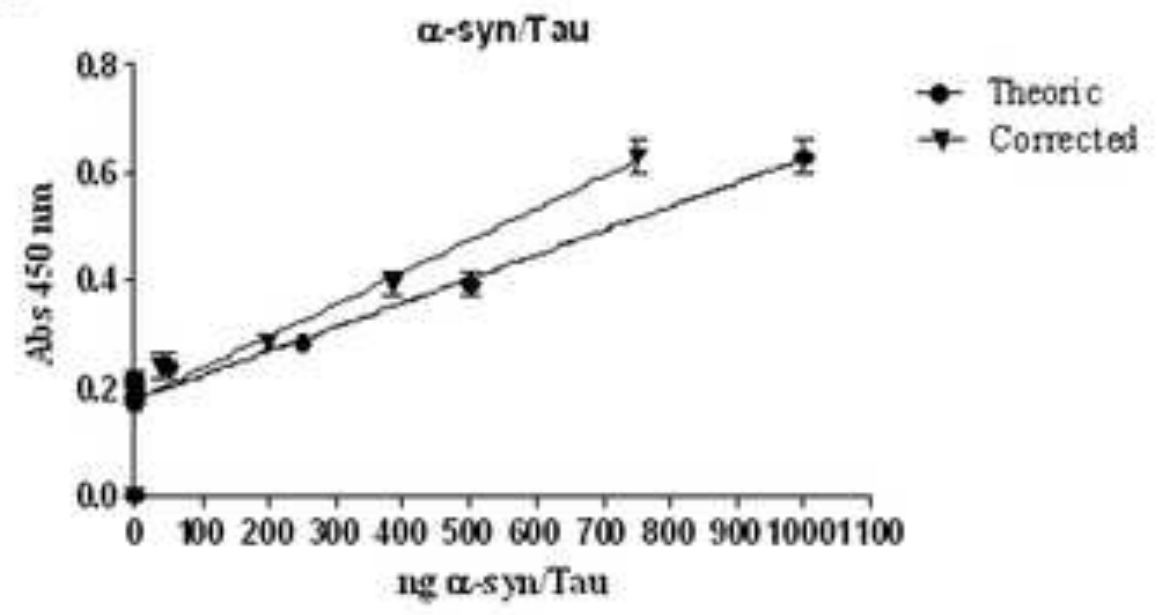


Figure 4
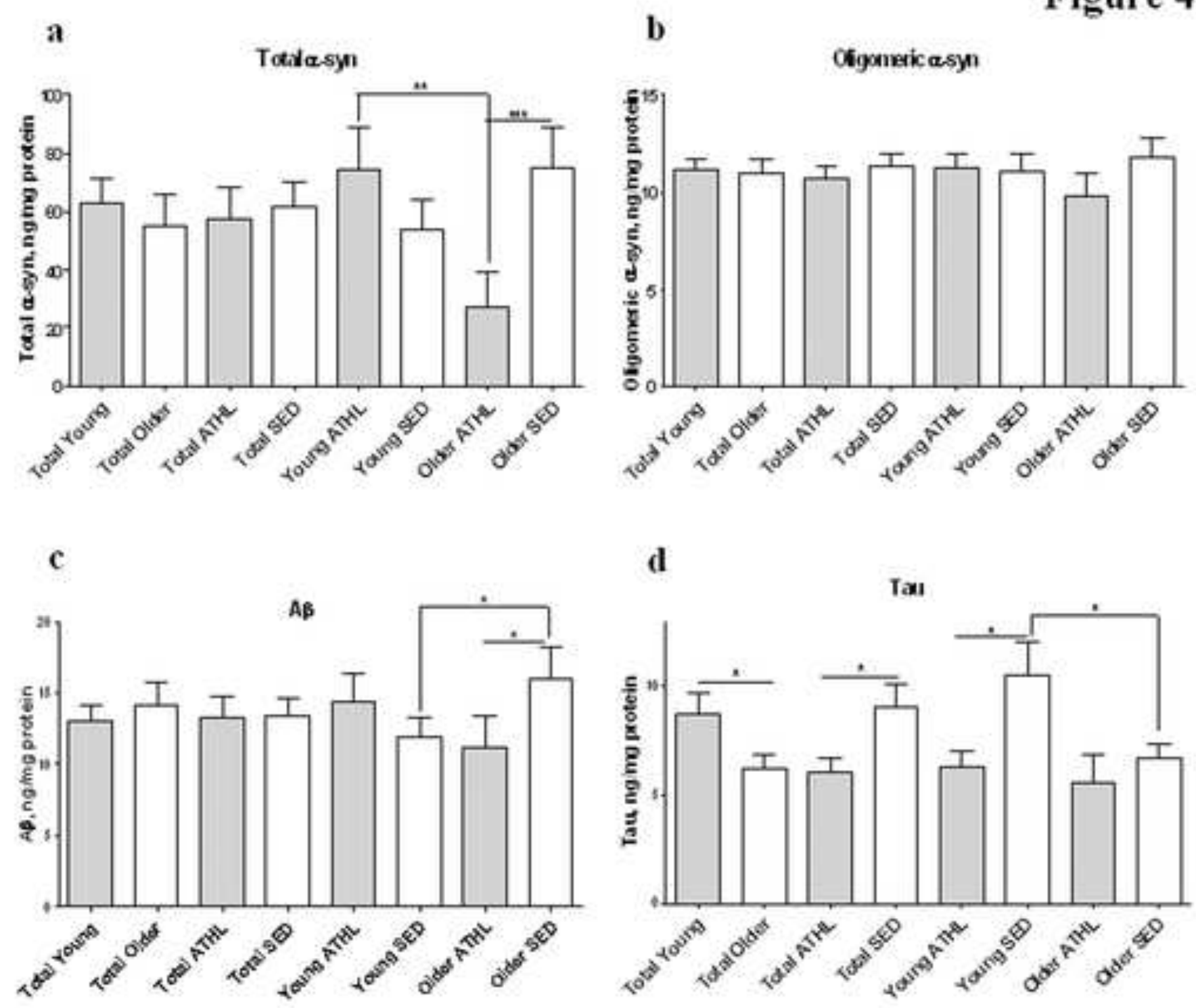

d

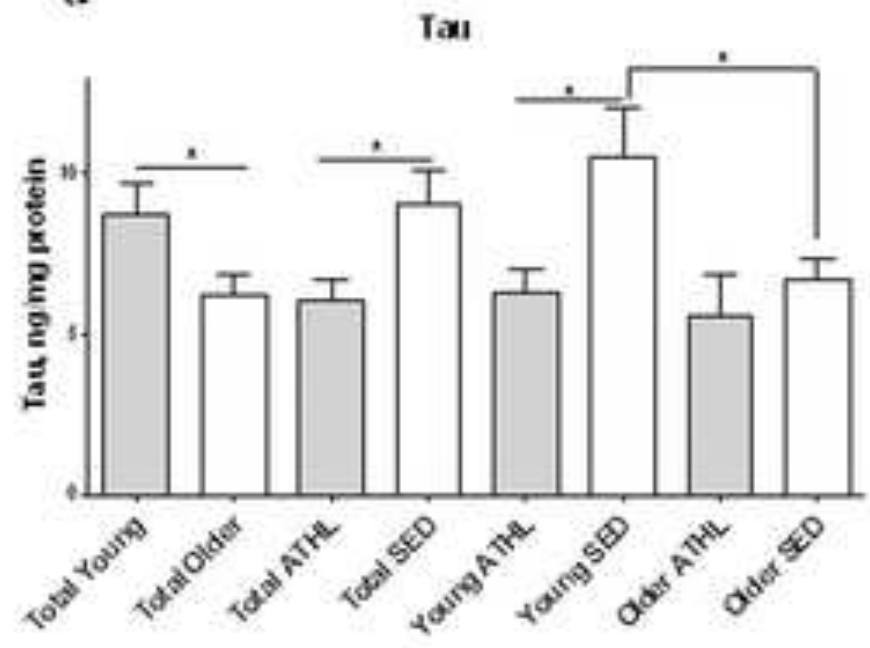

e

asymas

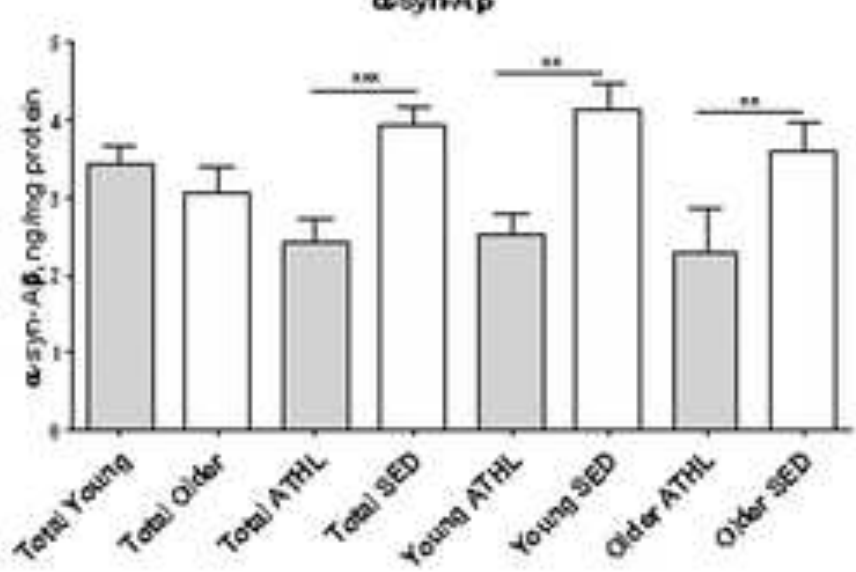

f

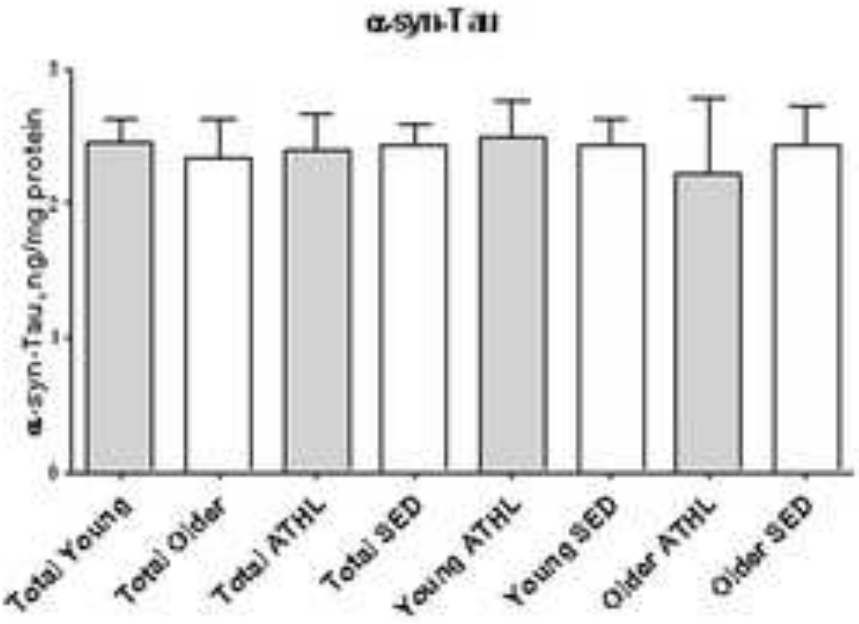


a

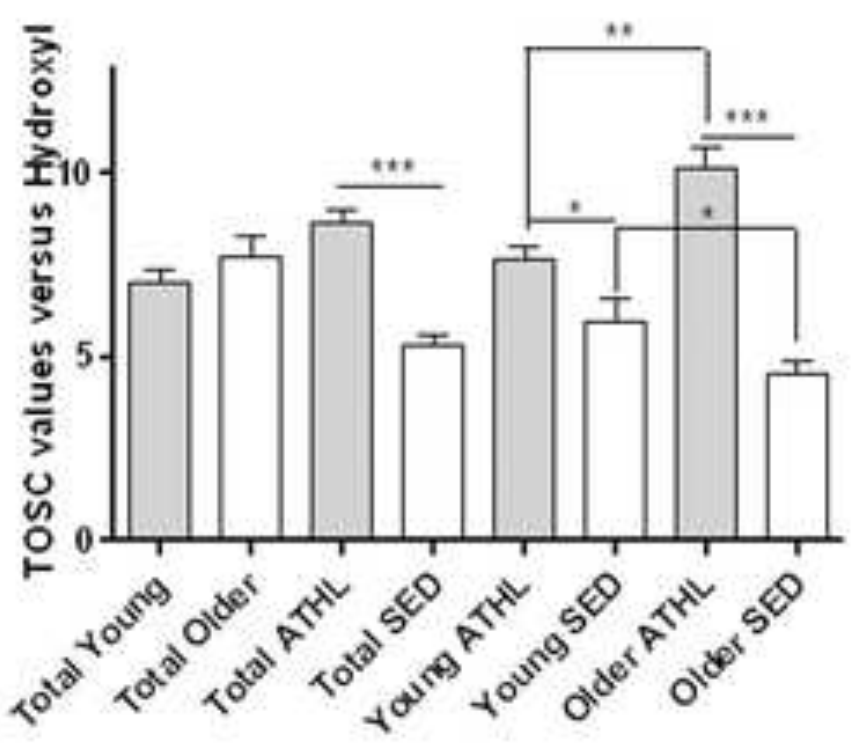

c Whole cohort

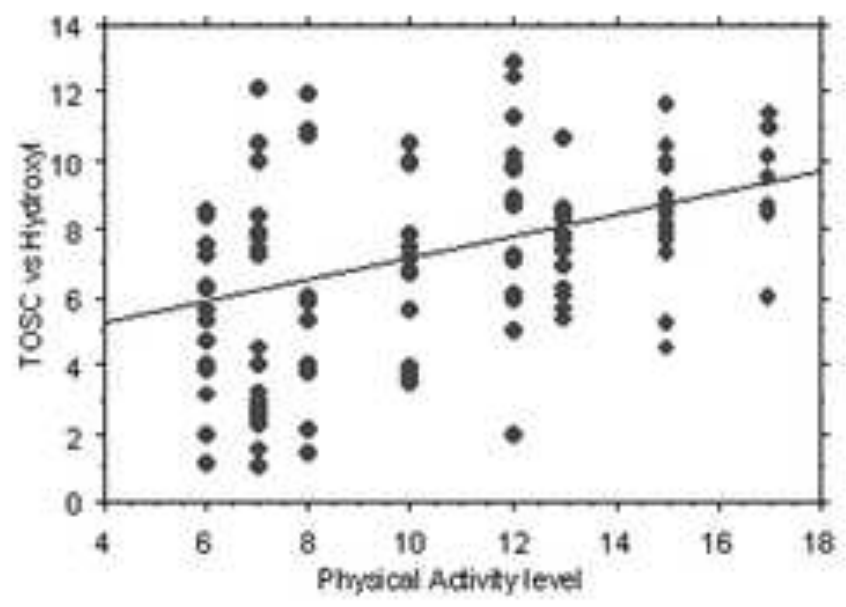

e

Young cohort

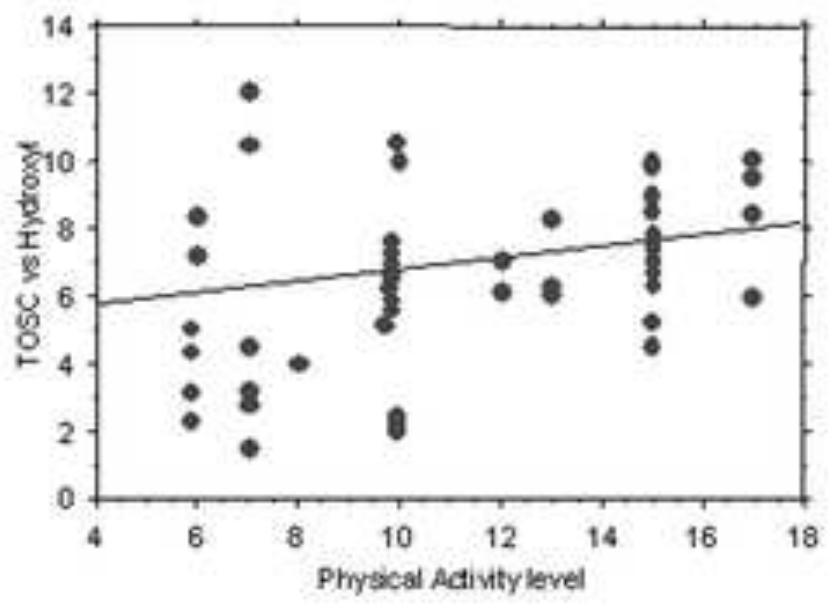

Figure 5

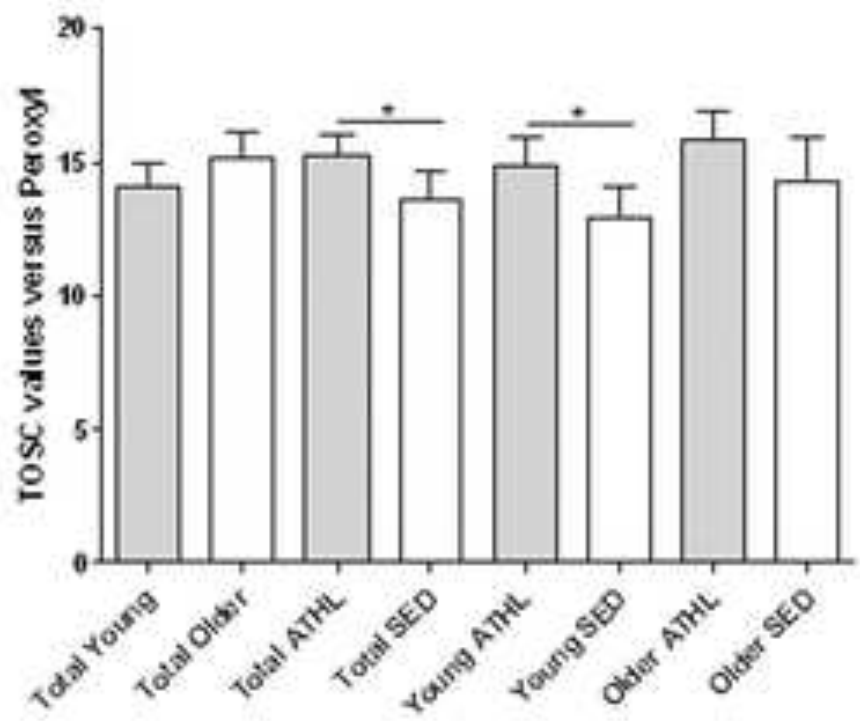

\section{d Older cohort}

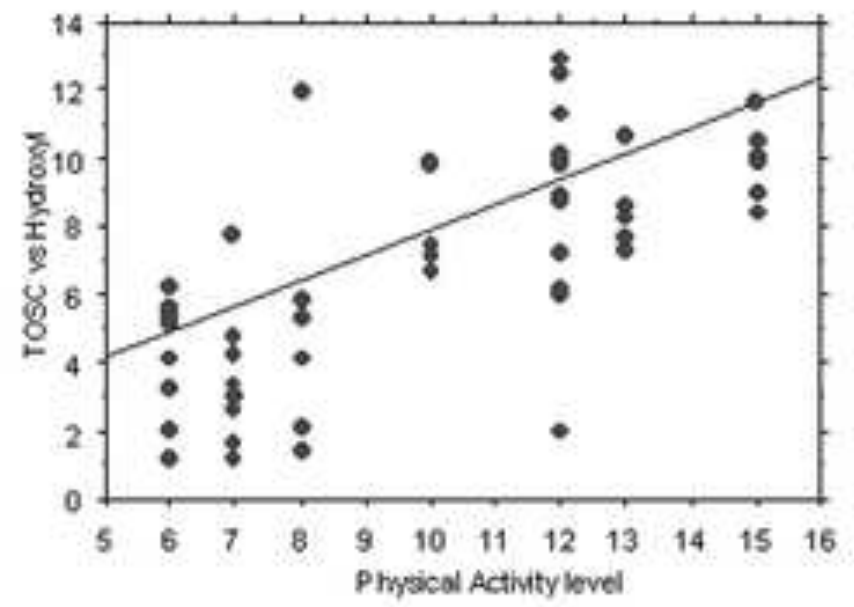

SED

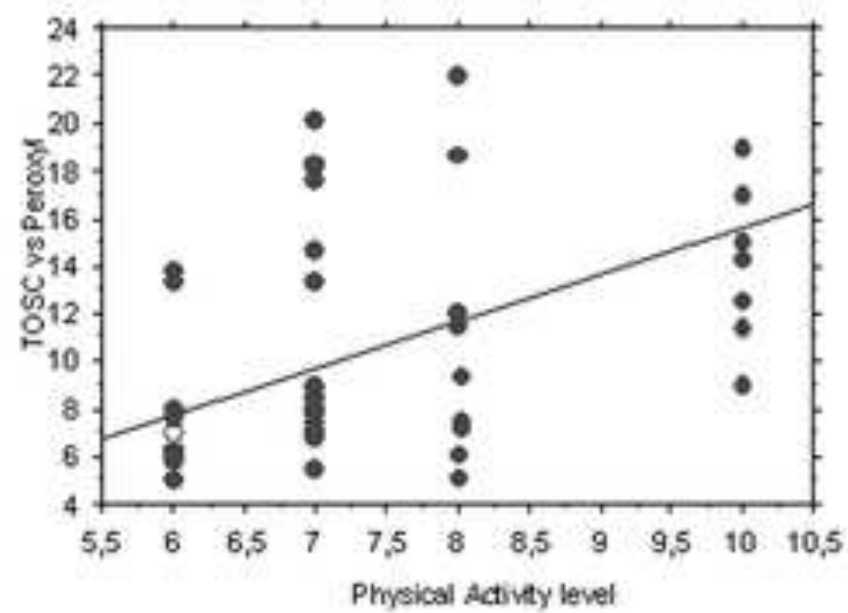


Figure 6

\section{a Total cohort}

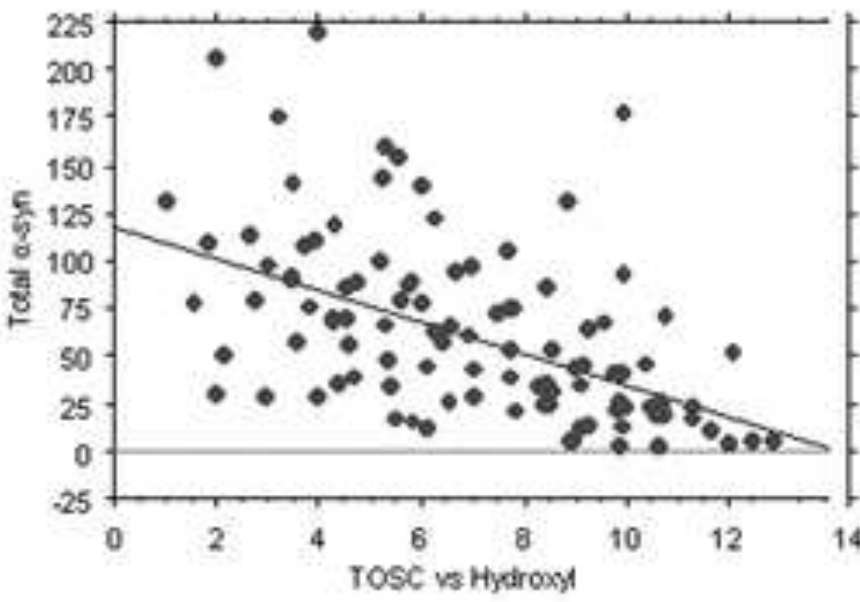

c
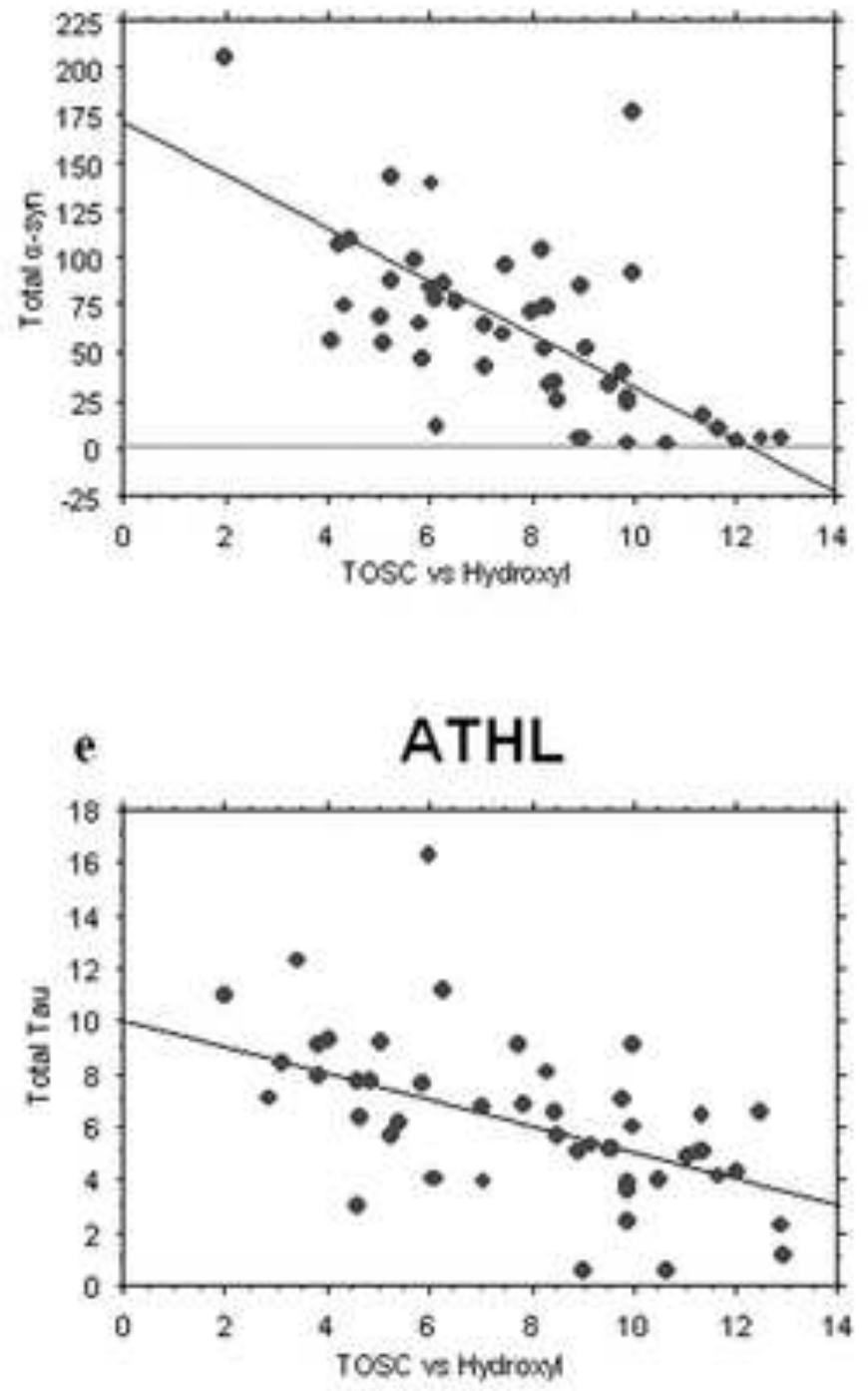

\section{b Older cohort}

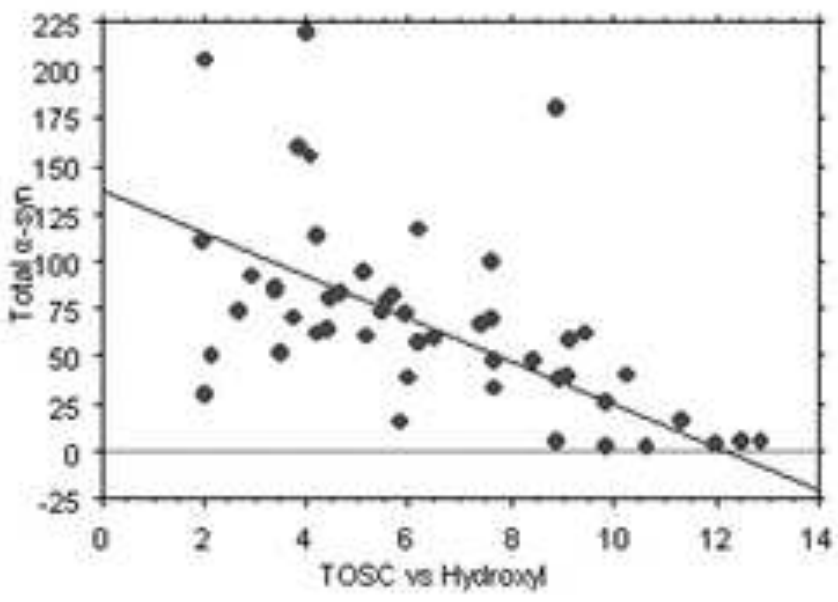

\section{d Older cohort}

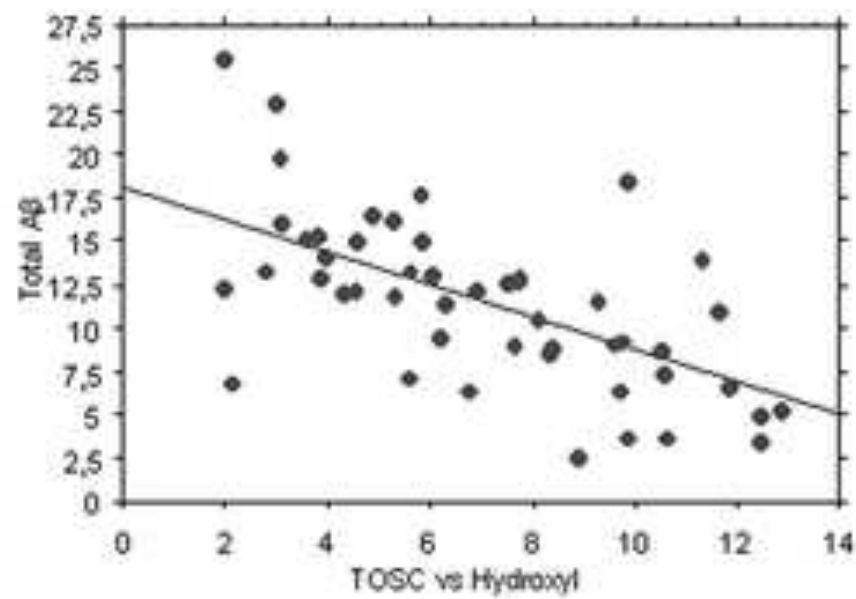


Figure 7

a Total cohort

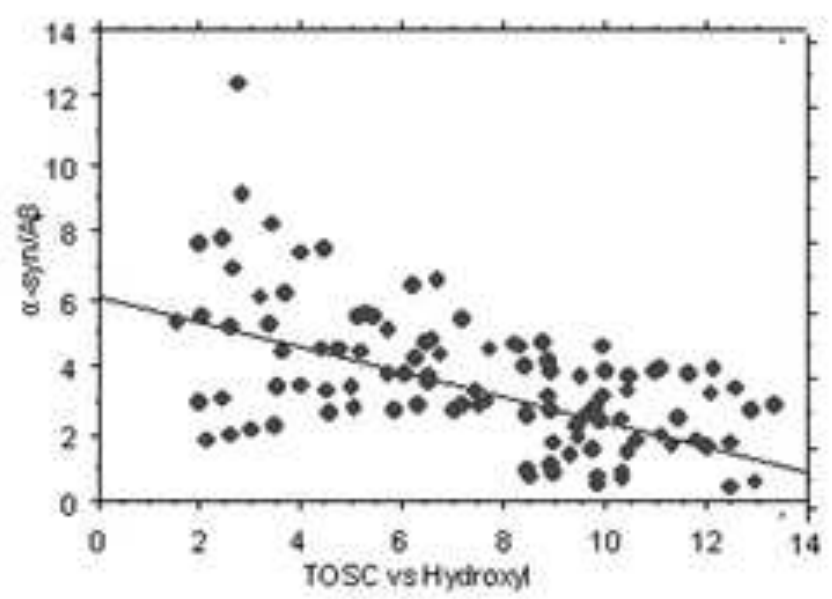

c Young cohort

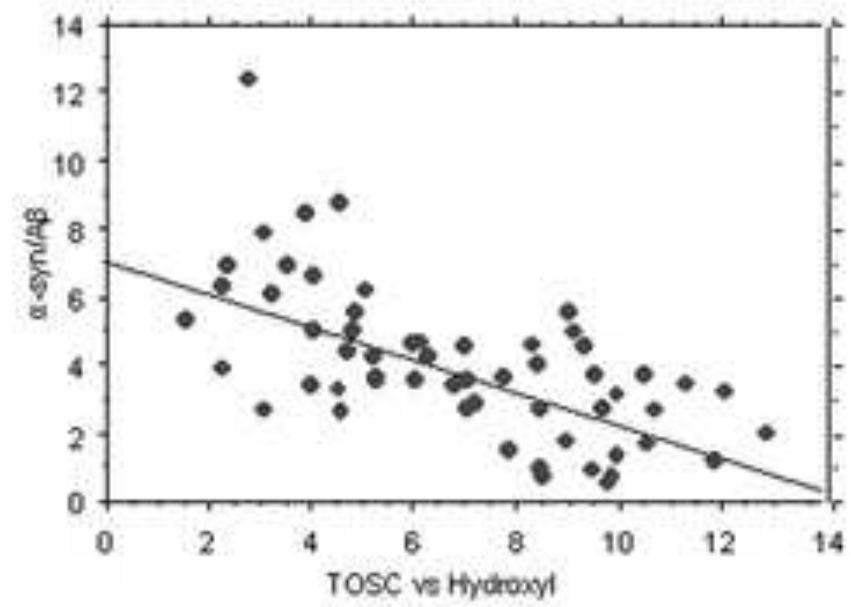

e SED

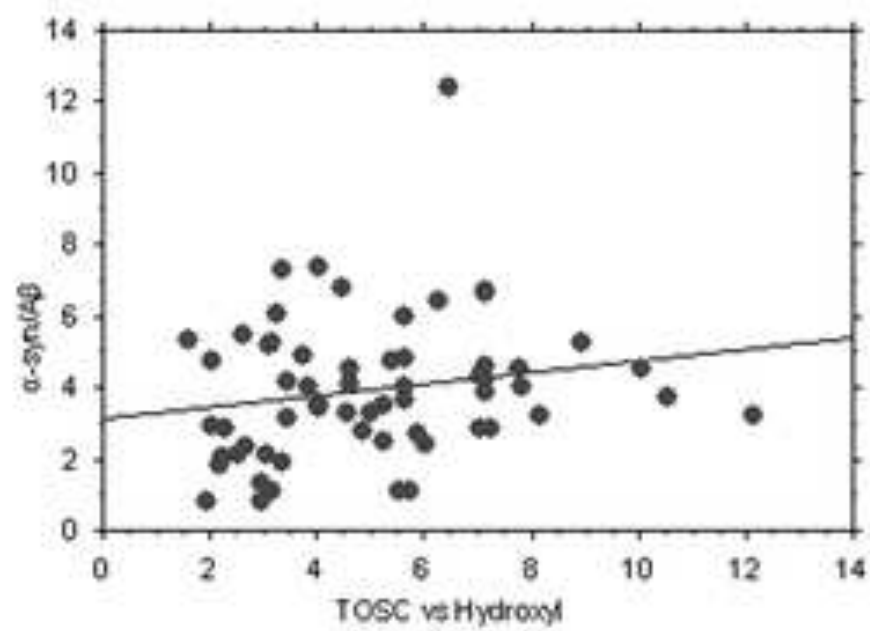

b Older cohort

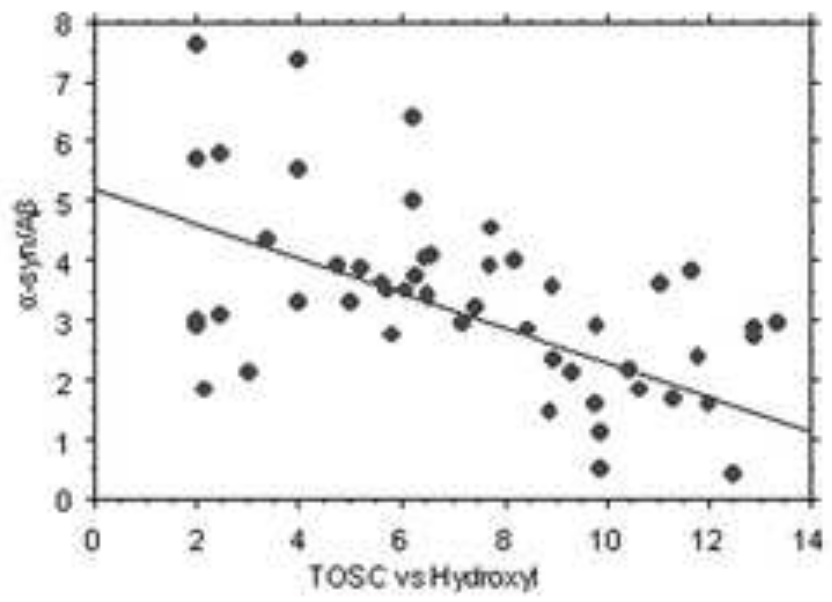

d $\quad$ ATHL

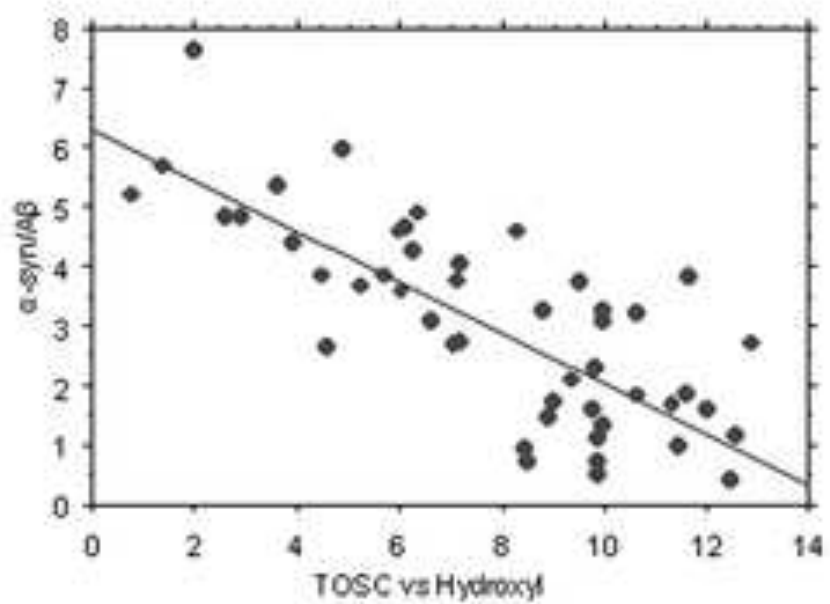


Figure 8

\section{a Total cohort}

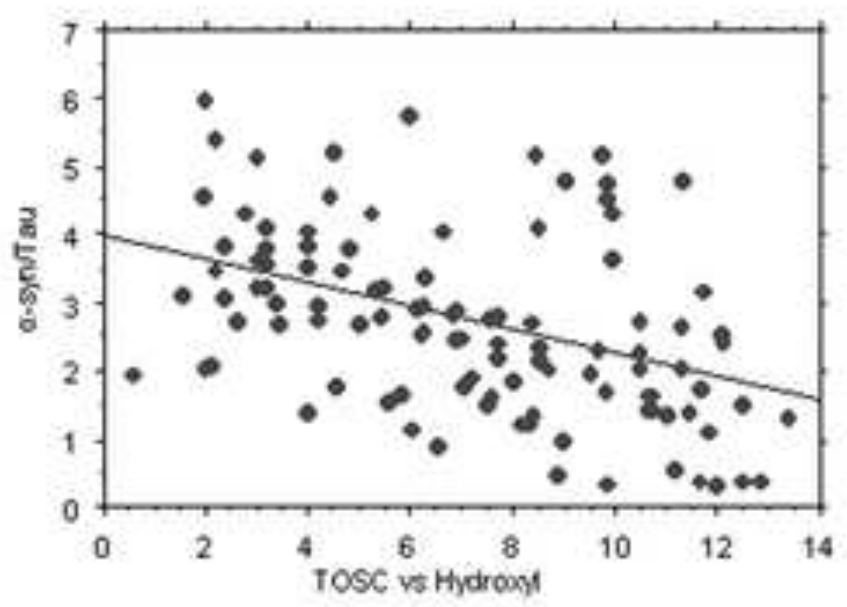

c

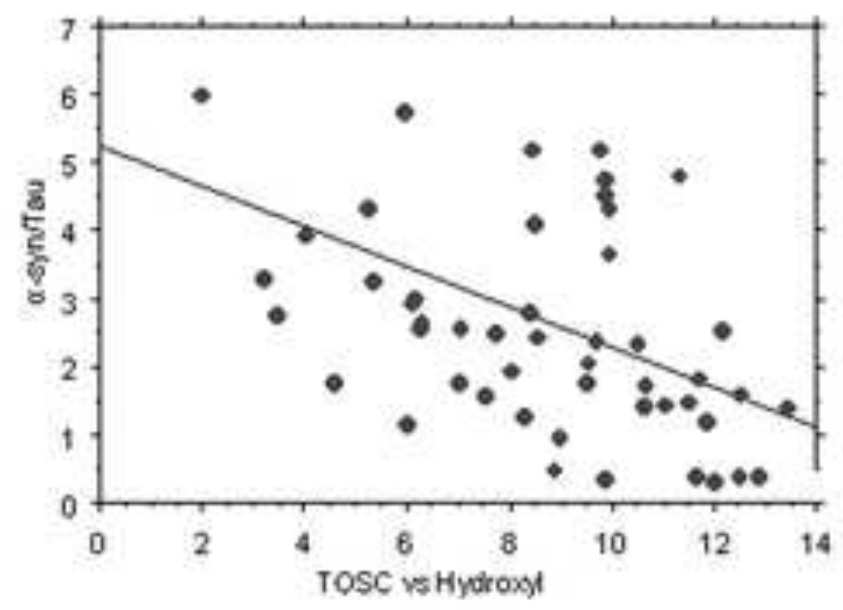

e Young cohort

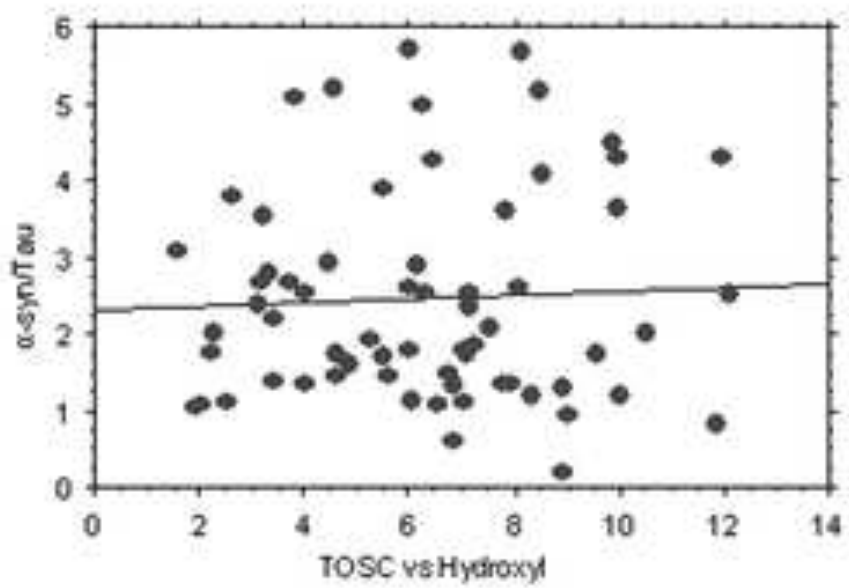

b Older cohort

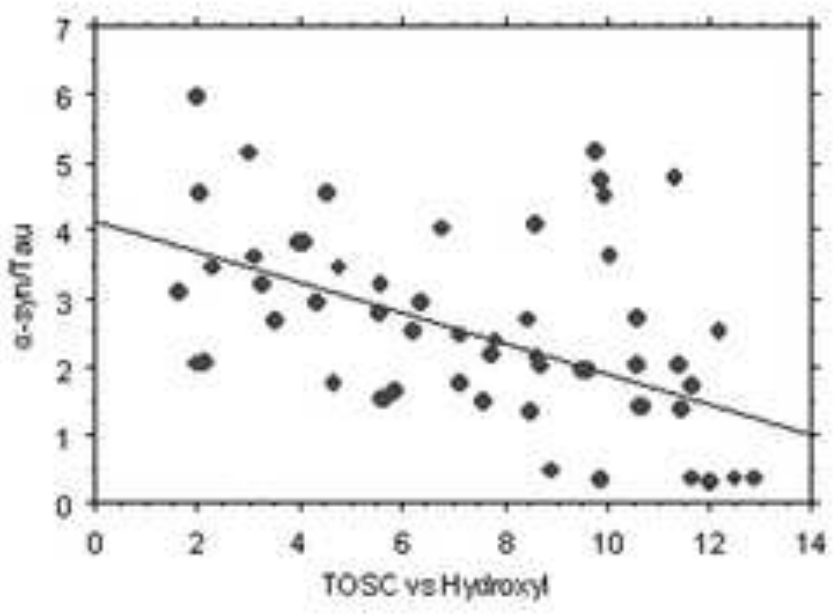

d SED

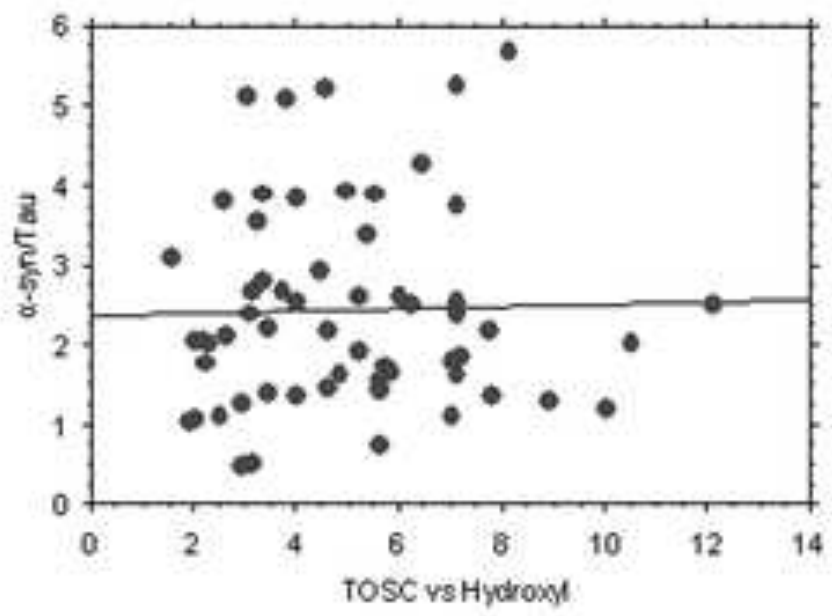



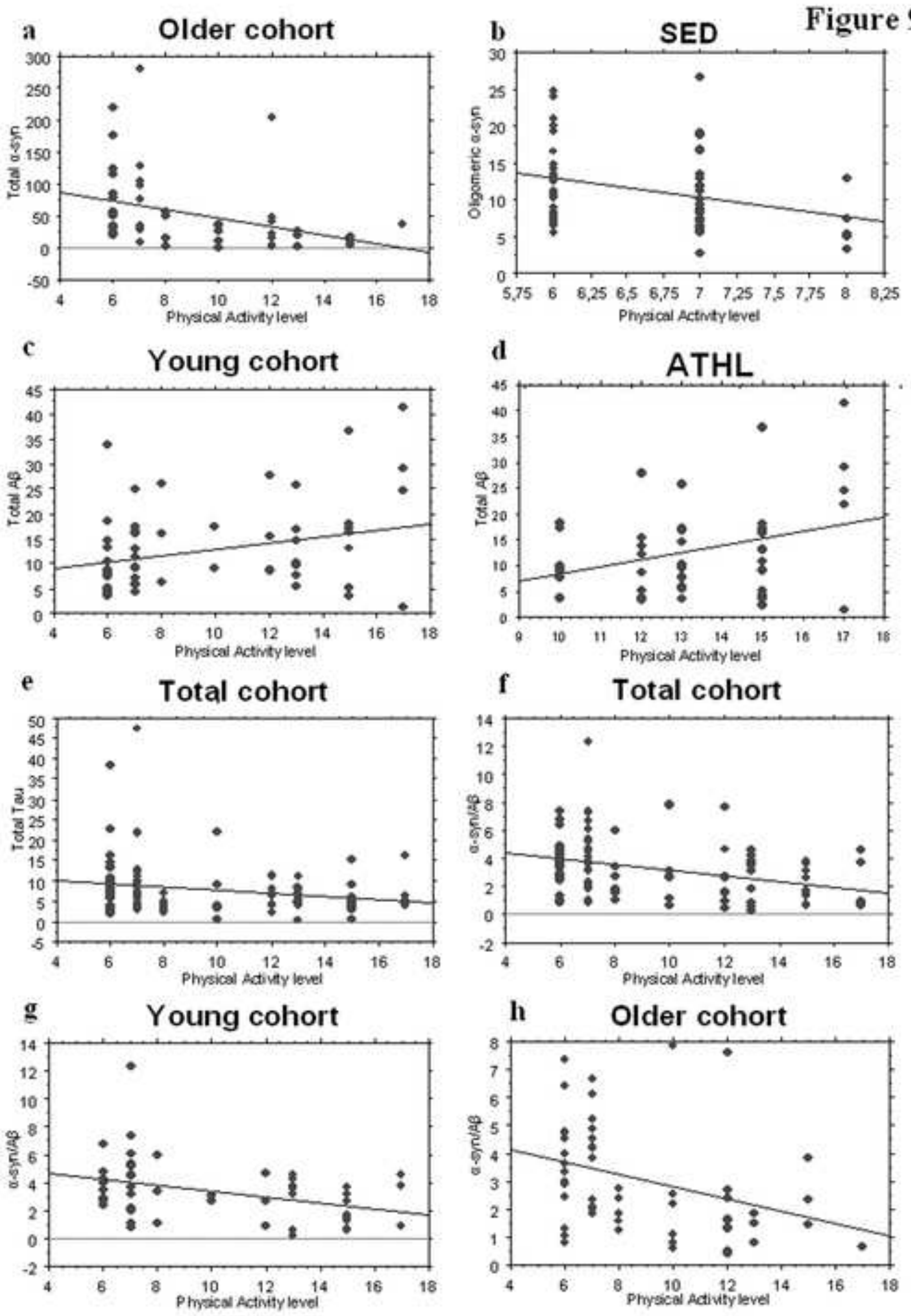


\section{Non $\varepsilon 4$ carriers}

Figure 10
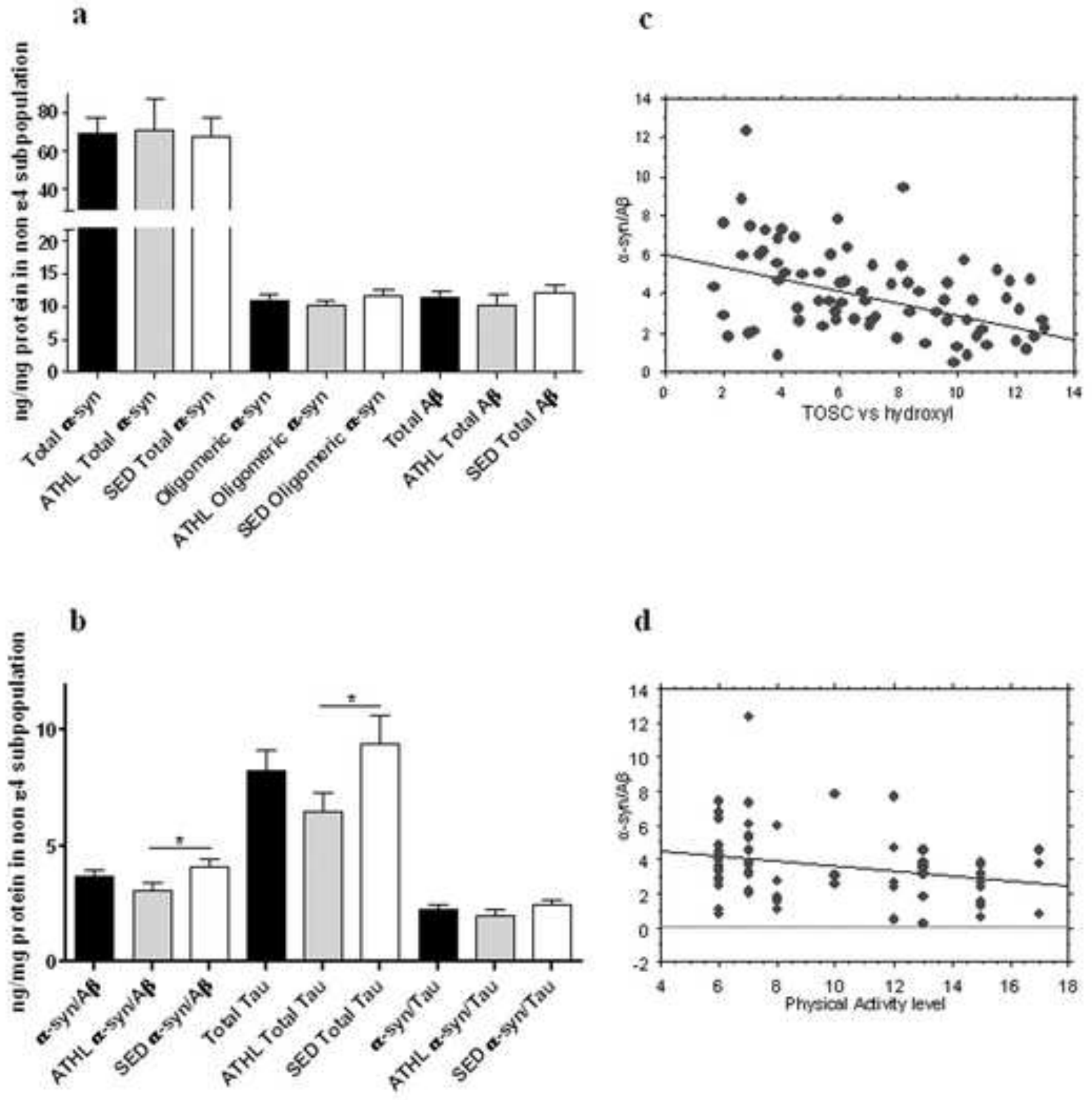

d

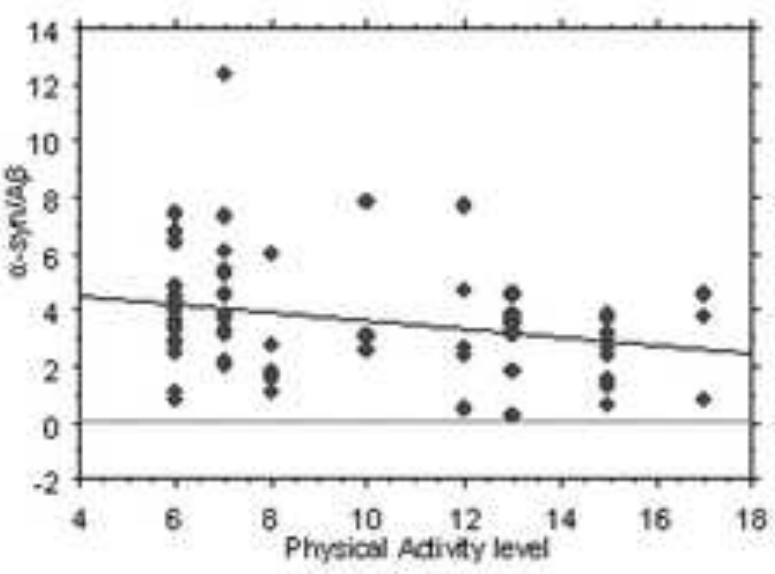




\section{4 carriers}

Figure 11

a

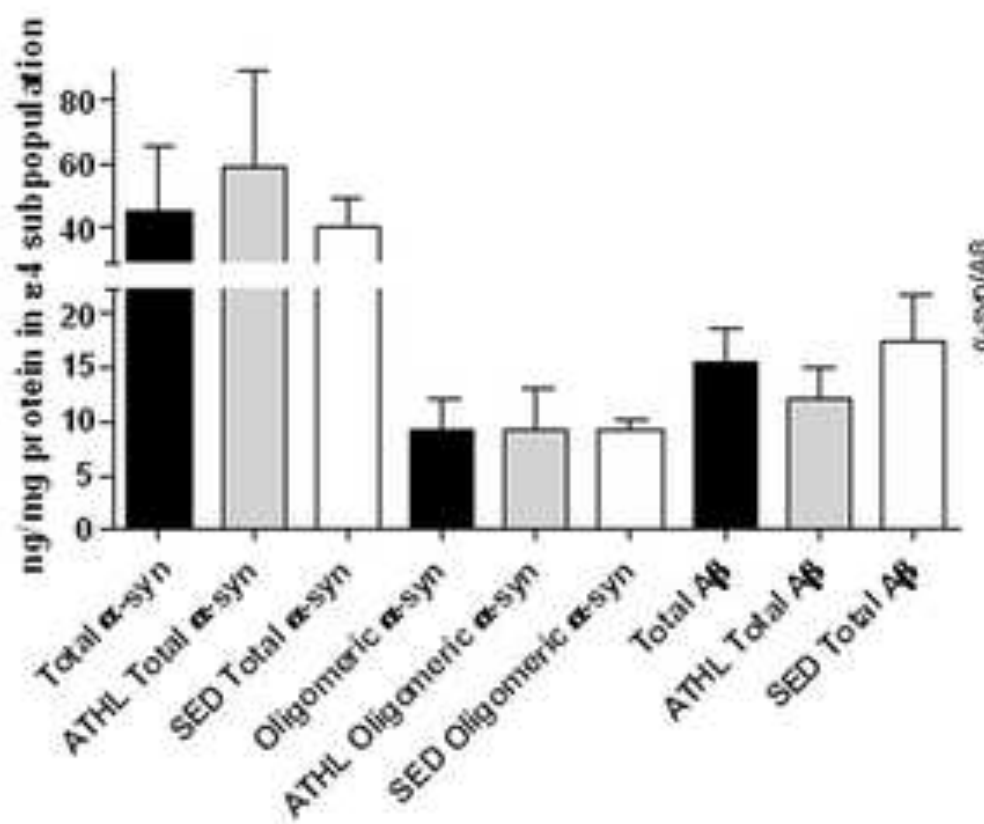

b

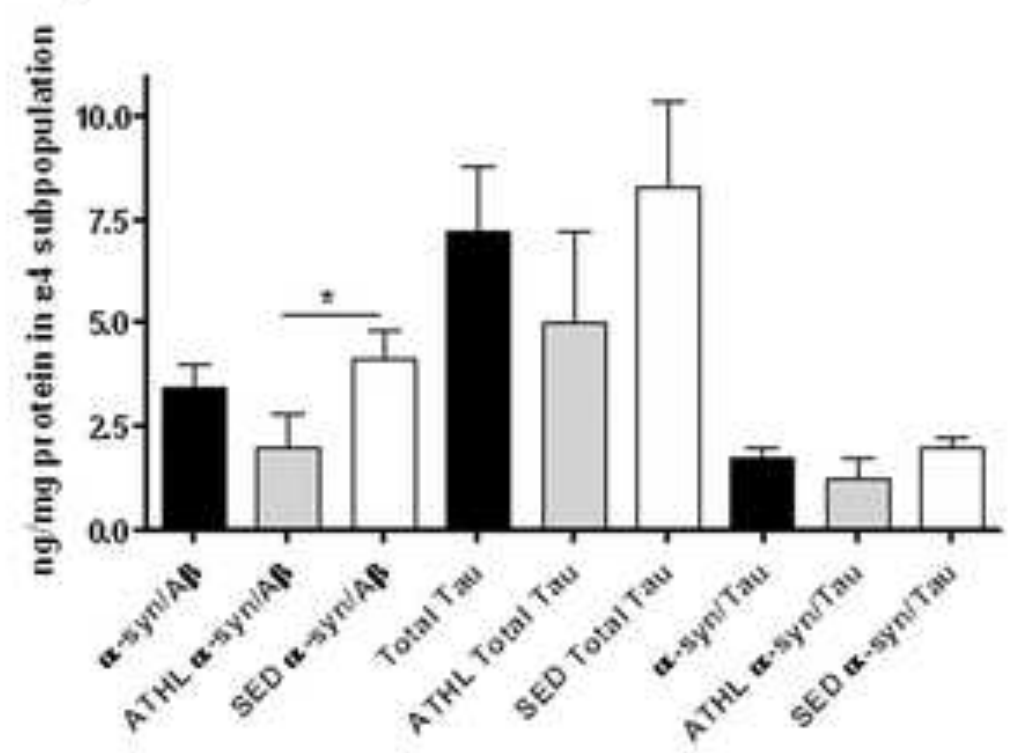

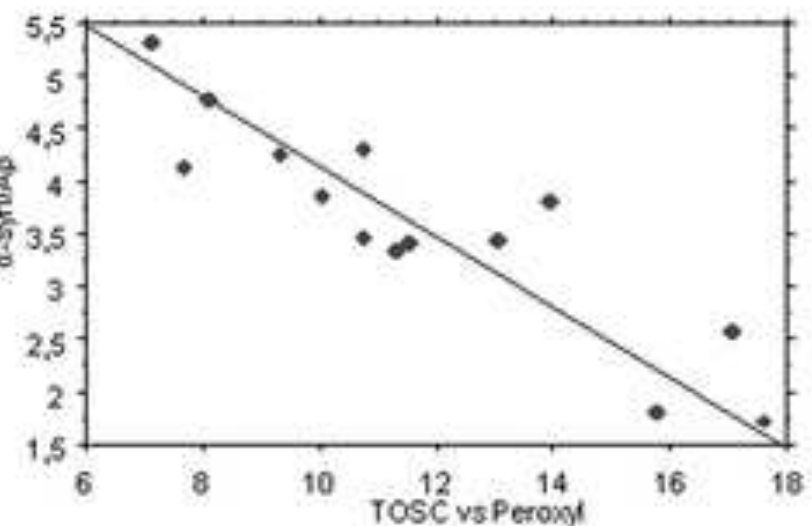

c 
Table 1. Descriptive analysis of the total population and of the subgroups. The data are the mean \pm SD.

\begin{tabular}{|c|c|c|c|c|c|}
\hline & $\begin{array}{l}\text { Number of } \\
\text { subjects (N) }\end{array}$ & Age (y) & BMI & Heart rate & $\begin{array}{c}\text { Physical } \\
\text { activity leve }\end{array}$ \\
\hline Young subjects & 56 & $35.5 \pm 9.6$ & $23.8 \pm 1.8$ & $55.4 \pm 3.3$ & $9.71 \pm 3.83$ \\
\hline Older subjects & 50 & $60.4 \pm 6.9$ & $24.6 \pm 2.1$ & $60.30 \pm 5.65$ & $8.79 \pm 3.15$ \\
\hline $\begin{array}{l}\text { ATHL (Total } \\
\text { cohort) }\end{array}$ & 48 & $44.6 \pm 13.5$ & $23.8 \pm 1.8$ & $52.6 \pm 3.6$ & $13.2 \pm 2.2$ \\
\hline SED (Total cohort) & 58 & $46.7 \pm 14.5$ & $24.4 \pm 1.9$ & $63.1 \pm 5.4$ & $6.61 \pm 0.64$ \\
\hline Young ATHL & 22 & $35.8 \pm 8.0$ & $23.4 \pm 1.6$ & $50.2 \pm 3.9 *$ & $13.75 \pm 2.05$ \\
\hline Young SED & 26 & $36.3 \pm 9.2$ & $24.2 \pm 1.20$ & $60.5 \pm 2.6$ & $6.70 \pm 0.59$ \\
\hline Older ATHL & 22 & $57.4 \pm 6.7$ & $24.1 \pm 0.8$ & $54.9 \pm 3.2 *$ & $12.3 \pm 2.1$ \\
\hline Older SED & 32 & $61.2 \pm 8.0$ & $25.1 \pm 0.9$ & $65.7 \pm 8.1$ & $6.50 \pm 0.68$ \\
\hline Non \&4 carrier & 73 & $44.4 \pm 14.2$ & $24.1 \pm 1.1$ & $58.8 \pm 1.1$ & $9.1 \pm 3.4$ \\
\hline $\begin{array}{c}\text { ATHL non } \varepsilon 4 \\
\text { carrier }\end{array}$ & 29 & $41.1 \pm 12.8$ & $23.5 \pm 0.9$ & $53.4 \pm 0.7$ & $13.3 \pm 2.3$ \\
\hline SED non 84 carrier & 44 & $46.6 \pm 14.7$ & $24.6 \pm 1.2$ & $64.2 \pm 1.4$ & $6.57 \pm 0.66$ \\
\hline$\varepsilon 4$ carrier & 14 & $39.3 \pm 14.3$ & $24.0 \pm 1.1$ & $56.1 \pm 1.4$ & $9, .0 \pm 3, .1$ \\
\hline ATHL $\varepsilon 4$ carrier & 6 & $41.5 \pm 21.0$ & $23,7 \pm 0.8$ & $51.2 \pm 1.2$ & $13.3 \pm 2.6$ \\
\hline SED \&4 carrier & 8 & $38.3 \pm 11.3$ & $24.3 \pm 1.3$ & $60.9 \pm 1.5$ & $6.87 \pm 064$ \\
\hline
\end{tabular}

BMI, Body Mass Index; ATHL, Athletes, SED, sedentary. $*$ P $<.001$ vs sedentary subgroups 
Table 2, TOSC values against hydroxyl and peroxyl radicals; concentrations of total $\alpha$-syn, oligemeric $\alpha$-syn, A $\beta, \alpha$-syn/A $\beta$, tau and $\alpha$-syn/tau (expressed as $\mathrm{ng} / \mathrm{mg}$ protein) in the indicate subgroups. The values are expressed as mean $\pm \mathrm{SD}$.

\begin{tabular}{|c|c|c|c|c|c|c|c|c|}
\hline & $\begin{array}{c}\text { TOSC values } \\
\text { (Peroxyl) }\end{array}$ & $\begin{array}{c}\text { TOSC values } \\
\text { (Hydroxyl) }\end{array}$ & Total $\alpha$-syn & Oligomeric $\alpha$-syn & $\mathbf{A \beta}$ & $\alpha-\operatorname{syn} / \mathbf{A} \beta$ & Tau & $\alpha-s y n /$ tau \\
\hline Young subjects & $14.1 \pm 3.5$ & $7.05 \pm 2.74$ & $62.6 \pm 50.0$ & $11.1 \pm 5.0$ & $13.0 \pm 9.2$ & $3.44 \pm 1.99$ & $8.70 \pm 7.68$ & $2.46 \pm 1.34$ \\
\hline Older subjects & $15.2 \pm 4.3$ & $7.79 \pm 3.82$ & $54.9 \pm 45.9$ & $11.0 \pm 4.7$ & $14.1 \pm 10.2$ & $3.07 \pm 2.09$ & $6.21 \pm 4.11$ & $2.35 \pm 1.74$ \\
\hline $\begin{array}{c}\text { ATHL (Total } \\
\text { cohort) }\end{array}$ & $15.3 \pm 3.9$ & $8.70 \pm 2.65$ & $57.4 \pm 43.8$ & $10.7 \pm 4.3$ & $13.3 \pm 9.7$ & $2.45 \pm 1.79$ & $6.05 \pm 4.20$ & $2.39 \pm 1.79$ \\
\hline SED (Total cohort) & $14.0 \pm 2.7$ & $5.34 \pm 2.05$ & $61.6 \pm 44.6$ & $11.3 \pm 5.3$ & $13.4 \pm 9.6$ & $3.94 \pm 1.97$ & $9.07 \pm 7.83$ & $2.44 \pm 1.24$ \\
\hline Young ATHL & $14.9 \pm 3.6$ & $7.66 \pm 1.85$ & $74.3 \pm 60.2$ & $11.2 \pm 4.1$ & $14.4 \pm 10.1$ & $2.53 \pm 1.47$ & $6.32 \pm 3.67$ & $2.49 \pm 1.53$ \\
\hline Young SED & $12.9 \pm 3.0$ & $6.03 \pm 3.10$ & $53.8 \pm 40.8$ & $11.0 \pm 5.7$ & $11.9 \pm 6.5$ & $4.14 \pm 2.07$ & $10.5 \pm 8.3$ & $2.44 \pm 1.19$ \\
\hline Older ATHL & $15.8 \pm 3.5$ & $10.1 \pm 3.0$ & $26.8 \pm 19.5$ & $9.8 \pm 4.6$ & $11.1 \pm 8.6$ & $2.30 \pm 1.31$ & $5.59 \pm 4.12$ & $2.22 \pm 1.74$ \\
\hline Older SED & $15.3 \pm 3.0$ & $4.57 \pm 2.10$ & $74.5 \pm 59.8$ & $11.8 \pm 4.7$ & $16.0 \pm 7.9$ & $3.60 \pm 1.80$ & $6.67 \pm 3.28$ & $2.44 \pm 1.34$ \\
\hline Non $\& 4$ carrier & $15.4 \pm 4.3$ & $7.06 \pm 3.24$ & $68.6 \pm 53.3$ & $11.1 \pm 5.3$ & $11.3 \pm 8.4$ & $3.69 \pm 2.03$ & $8.26 \pm 7.55$ & $2.27 \pm 1.43$ \\
\hline $\begin{array}{l}\text { ATHL non } 84 \\
\text { carrier }\end{array}$ & $16.8 \pm 3.1$ & $8.28 \pm 2.97$ & $70.6 \pm 66.0$ & $10.2 \pm 4.4$ & $10.3 \pm 7.8$ & $3.07 \pm 1.83$ & $6.45 \pm 3.92$ & $1.96 \pm 1.60$ \\
\hline $\begin{array}{l}\text { SED non } 84 \\
\text { carrier }\end{array}$ & $13.7 \pm 4.9$ & $5.69 \pm 3.06$ & $67.3 \pm 64.7$ & $11.6 \pm 5.9$ & $12.0 \pm 8.8$ & $4.09 \pm 2.07$ & $9.45 \pm 6.72$ & $2.47 \pm 1.30$ \\
\hline$\varepsilon 4$ carrier & $11.4 \pm 4.5$ & $5.19 \pm 3.18$ & $45.7 \pm 20.3$ & $9.18 \pm 3.03$ & $15.5 \pm 11.0$ & $3.45 \pm 1.99$ & $7.23 \pm 5.49$ & $1.76 \pm 0.89$ \\
\hline ATHL $\varepsilon 4$ carrier & $13.5 \pm 5.9$ & $7.63 \pm 1.91$ & $59.0 \pm 30.4$ & $9.4 \pm 3.96$ & $12.1 \pm 6.1$ & $2.03 \pm 1.55$ & $5.02 \pm 4.47$ & $1.27 \pm 0.99$ \\
\hline SED \&4 carrier & $9.3 \pm 3.1$ & $2.76 \pm 1.73$ & $40.3 \pm 25.1$ & $9.20 \pm 2.78$ & $17.3 \pm 12.7$ & $4.17 \pm 1.86$ & $8.53 \pm 5.89$ & $2.00 \pm 0.79$ \\
\hline
\end{tabular}

BMI, Body Mass Index; ATHL, Athletes, SED, sedentary 


\section{Click here to access/download \\ Supplementary Material Supplementary Files.docx}

